\title{
EL PROCESO DE CAMBIO DEL TEJIDO EDILICIO Y LA CONFIGURACION DE LA IMAGEN HETEROGENEA DE LA CIUDAD LATINOAMERICANA. Caso de estudio: la transformación del tejido edilicio en las 70 manzanas fundacionales, ciudad de Córdoba, Argentina.
}

\author{
Omar Paris \\ Univ. Nacional de Córdoba / Univ. Católica de Córdoba. \\ Director: Dr. Arq. Joaquín Sabaté Bel (UPC) \\ Tutor local: Dr. Arq. Inés Moisset (UCC CONICET) \\ Asesora: Prof. Consulta Arq. Noemí Goytia (UNC) \\ Colaboración: Arq. Lucas Font \\ paris.omar.paris@gmail.com
}

\section{RESUMEN}

El presente artículo aborda el análisis morfológico del proceso de transformación del tejido edilicio como complemento de lo presentado en el SIIU de Montevideo 2015 donde abordamos la rugosidad en relación al proceso de fraccionamiento parcelario que es soporte del tejido motivo de este análisis. Las piezas técnicas elaboradas ad hoc constituyen un aporte al estudio urbano de la ciudad de Córdoba frente a la inexistencia de las mismas. Las palabras desorden y complicado, imperfección y caos, son utilizadas para calificar la imagen de la ciudad latinoamericana. ¿Es desorden?, ¿es caos?, ¿desde dónde nos posicionamos para hacer tales afirmaciones? La hipótesis que orienta esta investigación define a la irregularidad de la forma urbana como un valor positivo de las ciudades latinoamericanas. Se trata de una forma más de ciudad que las caracteriza e identifica. Habiendo identificado a la rugosidad urbana como un rasgo identitario, y con el deseo de construir criterios proyectuales operativos para actuar en el diseño urbano desde la heterogeneidad, vemos necesario hacer visible el proceso de generación de esta rugosidad en un caso de estudio específico: las 70 manzanas fundacionales de Córdoba, Argentina)

Palabras Clave: identidad, tejido edilicio, cuadricula, rugosidad.

\begin{abstract}
The present article addresses the morphological analysis of the process of transformation of the building fabric as a complement to what was presented in the SIIU in Montevideo 2015, where we approached the process of fragmentation that supports the fabric of the analysis. The technical pieces made ad hoc constitute a contribution to the urban study of the city of Cordoba. The words complicated and disorder, imperfection and chaos, are used to qualify the image of the Latin American city. Is disorder? is chaos?, where do we place ourselves to make such statements? Hypothesis: The irregularly shaped cities in Latin America is not a negative value. It is another form of city that characterizes and identifies it. Once we have known his generation process in a case study and having verified that as an identity in many other Latin American cities, we talk about a shared identity trait. Roughness: identity trait, wich defines features within the projectual process. This generating process is displayed in our study case: 70 Cordoba foundational blocks in Argentina and will establish an operational criteria as a way to act in urban design from heterogeneity.
\end{abstract}

Key words: Identity, building fabric, grid, roughness. 


\section{Introducción}

El presente artículo aborda el análisis morfológico del proceso de transformación del tejido edilicio como complemento de lo presentado en el SIIU de Montevideo 2015 donde abordamos al proceso de fraccionamiento parcelario que es soporte del tejido edilicio motivo de análisis en el presente artículo. (PARIS, El proceso de subdivisión parcelaria y la configuración de la imagen heterogénea de la ciudad latinoamericana. Caso de estudio: ciudad de Córdoba, Argentina., 2015)

Las palabras desorden y complicado, imperfección y caos, son utilizadas para calificar la imagen de la ciudad latinoamericana. ¿es desorden?, ¿es caos?, ¿desde dónde nos posicionamos para hacer tales afirmaciones? Se trata de una forma más de ciudad que las caracteriza e identifica.

Si conocemos su proceso de generación en un caso de estudio y verificamos que esta realidad se identifica en muchas otras ciudades latinoamericanas, estaremos hablando de un rasgo de identidad compartido.

"... hay que entender que el paisaje y el territorio son una realidad en continua evolución, como la sociedad que los crea, y que aquello que debe preocuparnos no es tanto asegurar su inmutabilidad -basándonos en la protección-, sino evitar que, en el natural proceso de transformación, el territorio y el paisaje se vean despojados de sus valores patrimoniales, simbólicos, en definitiva, de su identidad." (GALINDO GONZELEZ \& SABATE BEL, 2009)

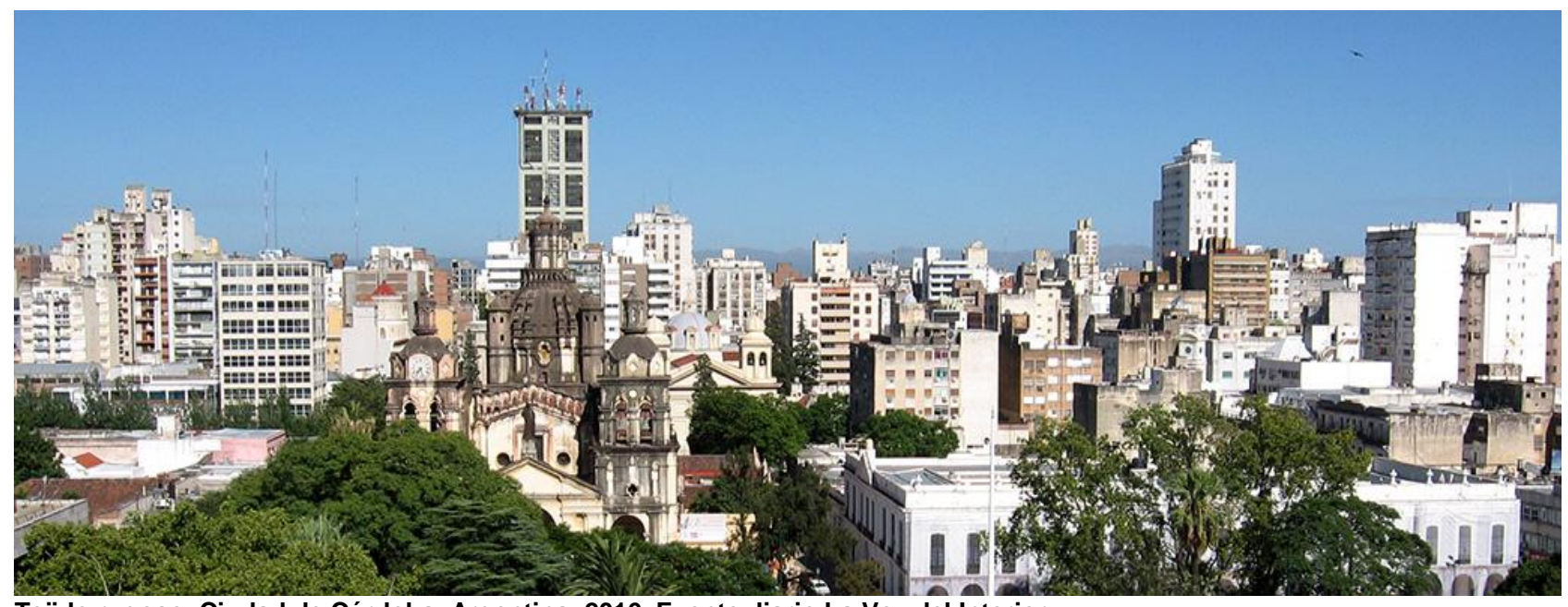

Tejido rugoso, Ciudad de Córdoba, Argentina, 2016. Fuente diario La Voz del Interior.

La hipótesis que orienta esta búsqueda investigativa es que la irregularidad y la diversidad que podemos observar a simple vista en la forma de las ciudades latinoamericanas de fundación hispana es un valor positivo. Se trata de un rasgo más que las caracteriza e identifica. Esta irregularidad a la cual nos referimos, cuyo soporte es un tejido edilicio conformado con granos de diversos tamaños y dispuestos de una manera aparentemente caprichosa, conforma una textura urbana a la cual calificamos como de carácter rugoso.

Si conocemos las causas, llevando a la luz el proceso de generación de esta rugosidad teniendo como objeto un caso de estudio (en este caso las 70 manzanas fundacionales de la ciudad de Córdoba) y verificamos que esta realidad se identifica en otras tantas ciudades latinoamericanas, estaremos hablando de un estado habitual que se constituye en un rasgo de identidad compartido.

El reconocer la rugosidad nos posibilita establecer criterios operativos para el accionar con variables que cualifican el paisaje urbano latinoamericano mientras acompañan la natural renovación en sus procesos de evolución urbana desde la heterogeneidad y la comprensión de sus características propias.

\section{La rugosidad en el tejido urbano}

El término rugosidad es abordado y definido en el Plan Especial del Ensanche de Barcelona (Ayuntamiento de Barcelona, 1983) de la siguiente manera: "es una medida del perfil superior de las casas indicando si el cielo se recorta en las cornisas y tejados de una forma más recta o cortada". 
La línea de cornisa "rota" que es posible apreciar se corresponde con el volumen posible de construir, o dicho de otra manera, con el faltante para la consolidación del modelo deseado: "es por eso que en el Ensanche quedan muchas medianeras vistas, fruto, en gran parte, de la alteración en el tiempo de la altura edificable y que es palpable en toda su extensión." (Ayuntamiento de Barcelona, 1983)

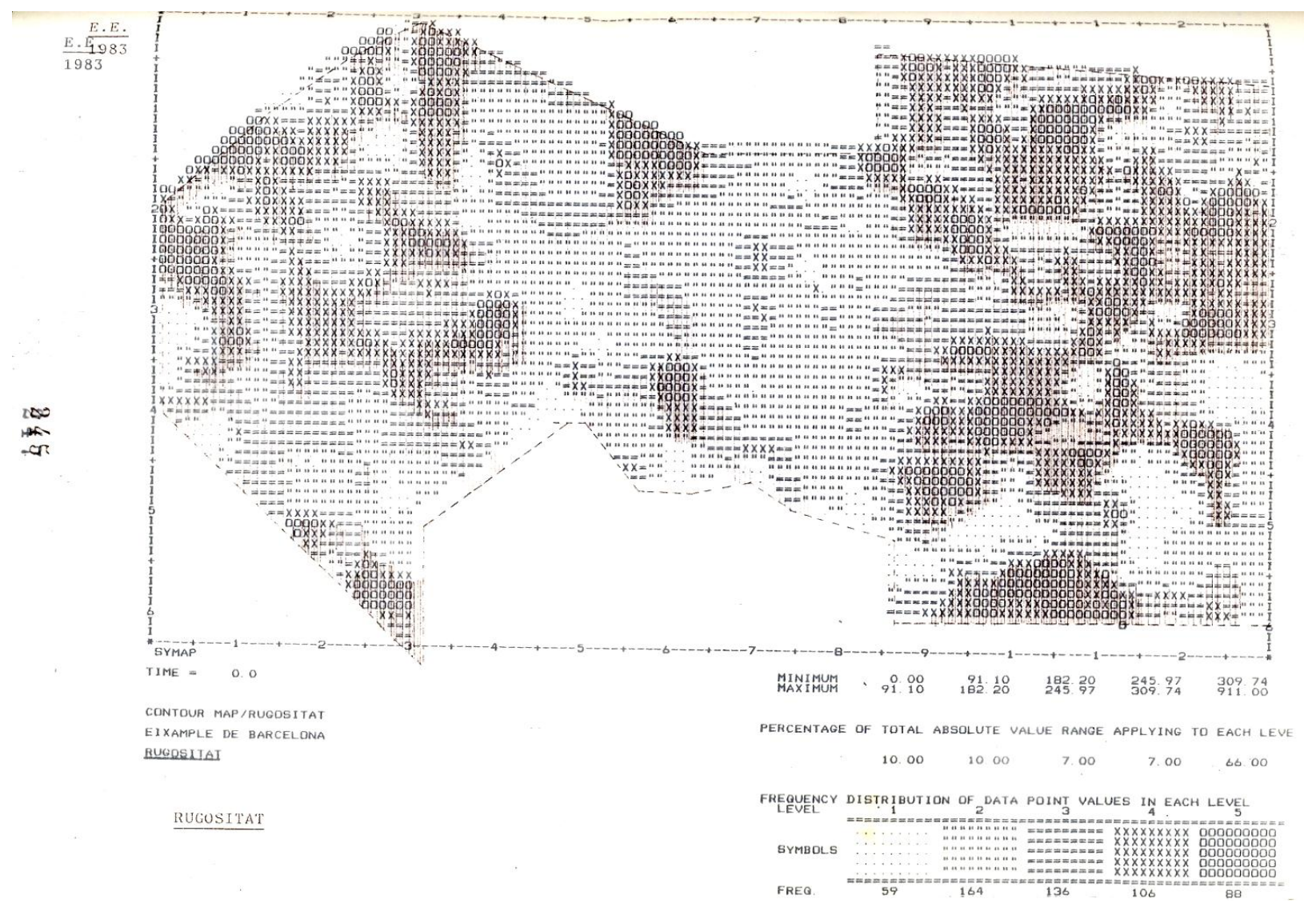

Plano 1078. Mapeo de la rugosidad en las manzanas del Ensanche. Plan Especial del Ensanche de Barcelona.

En este trabajo, llamamos rugosidad a la imagen producida por las diferencias de altura que se pueden encontrar dentro de las manzanas entre edificaciones de lotes próximos entre sí. Estas diferencias de altura generan una textura variada y heterogénea en cuanto a alturas y granos urbanos, y por consecuencia un "paisaje urbano rugoso".

El indicador de esta cualidad es la diferencia de alturas conviviendo en una superficie reducida. Por lo cual, diferencias significativas de alturas entre edificios próximos (colindantes y/o vecinos) dan como resultado una mayor rugosidad que si estos edificios tienen alturas similares y continuas. 


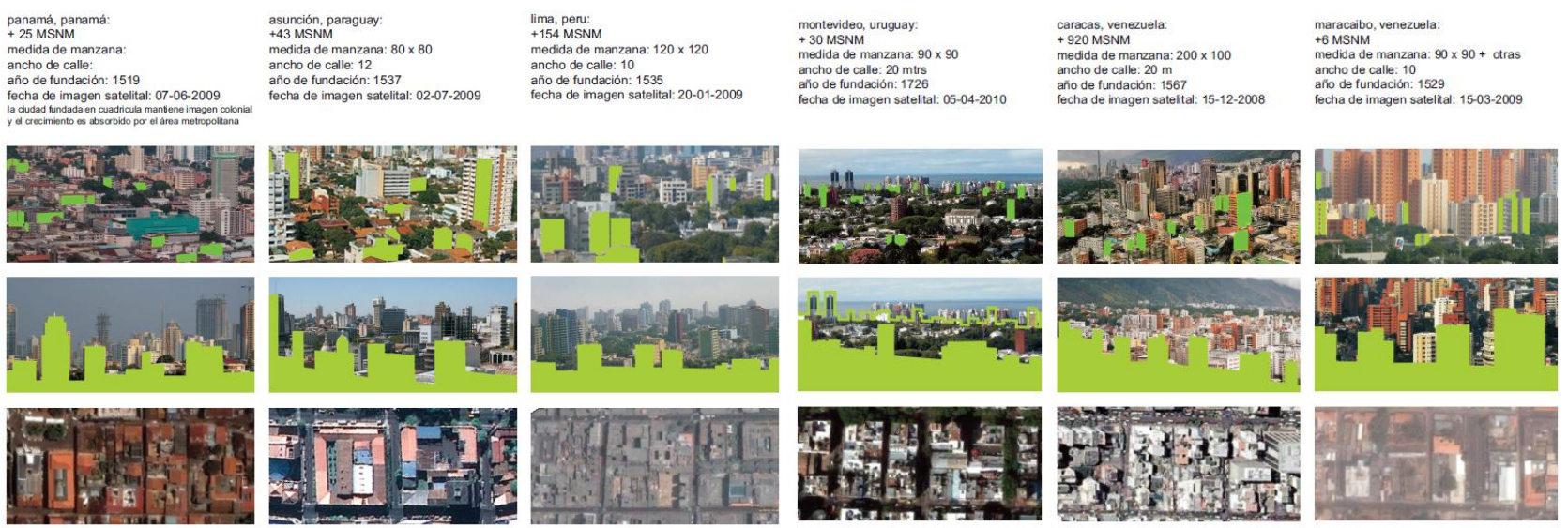

Grafica analítica de rugosidad urbana. Síntesis del análisis preliminar de 60 ciudades (las capitales + la segunda ciudad) de 30 países de Latinoamérica cuya fundación haya sido en cuadrícula y con población de más de $\mathbf{1 . 0 0 0 . 0 0 0}$ de habitantes. De las 60 ciudades 31 no calificaron por cantidad de habitantes. El objeto de análisis quedó reducido a 29 ciudades. En las imágenes se verifican las características de rugosidad y discontinuidad detectadas para la ciudad de Córdoba a partir de fotografías satelitales y panorámicas. Seminario de investigación, Doctorado en Urbanismo, ETSAB, UPC. Fuente: Elaboración propia.

Al abordar el tema de la forma urbana desde lo morfológico, sacamos del foco de atención a algunos hechos que pueden explicar el crecimiento o decrecimiento de una ciudad tales como los factores políticos, económicos y demográficos. Sin embargo este análisis, nos permite alcanzar una comprensión desde una mirada que relaciona a la problemática con el campo de lo identitario a partir de evidenciar los procesos que determinan la morfología urbana de la ciudad desde estas formas resultantes que son la expresión material de los factores mencionados anteriormente. (PANERAI \& Jean Charles DEPAULE, 1983).

Desde una mirada morfológica, entendemos el término tejido edilicio como un sistema formado por llenos y vacíos dentro de una parcela determinada (escala micro), que en su conjunto conforman la unidad manzana (escala meso) y la agrupación por proximidad conformando un conjunto mayor de estas últimas (macro) definen una textura urbana determinada que otorga características paisajísticas reconocibles.

Analizar la forma de este tejido en el tiempo nos permitirá mirar sus variaciones en cuanto a rugosidad y comprender su proceso de generación.

En el libro Proyectar la Ciudad (PANERAI \& MANGIN, Proyectar la ciudad., 2002) relaciona a la diversidad en los tejidos urbanos de las ciudades con el proceso de sustitución desde su origen al día de hoy:

"Con excepción de ciertos barrios centrales de las grandes metrópolis, las ciudades contienen generalmente varios tipos de edificios mezclados, bien porque sobre el trazado inicial, desde su origen y de una forma ordenada y voluntaria, coexistieran edificios diferentes, o bien porque a partir de una ordenación homogénea el proceso de sustitución haya llevado progresivamente a la diversidad de la edificación".

También los autores señalan que un mayor o menor grado de regularidad en los tejidos urbanos se relaciona a la cultura mencionando que los países anglosajones y de cultura flamenca son los más regulares y los otros (no especifica cuales culturas) más irregulares:

"Los tejidos urbanos de Londres, Bruselas, Florencia, Montreal, Milán o Buenos Aires presentan, en los barrios del siglo XIX o de principio del XX, yuxtaposiciones similares, que se regulan de modo más riguroso en los países de cultura inglesa o flamenca y más flexible en los demás."

Panerai y Mangin reconocen a la diversidad en el tejido urbano y marcan como una de sus causas al tejido edilicio y sus cambios en el tiempo.

Sin embargo, en la actualidad este fenómeno de irregularidad se da también en las periferias de las ciudades intermedias españolas: En los estudios de Miquel Corominas sobre los orígenes del Ensanche de Barcelona (COROMINAS I AYALA, 2002) se reconoce a la arquitectura y a los tipos arquitectónicos a los cuales adscriben como protagonistas en la definición de la forma resultante de la ciudad.

En el contexto cordobés, sucede lo mismo con los estudios de Foglia y Goytia sobre la cuadricula (FOGLIA, GOYTIA, \& otros, 1987) donde ordenan las arquitecturas de cada periodo logrando tipificarlas para su estudio y haciendo inferencias sobre la configuración de la imagen de la ciudad de Córdoba. Por otro lado, la historiadora cordobesa Boixiados en su libro Las tramas de una ciudad, Córdoba entre 1870 y 1895 (BOIXADÓS, 2000), aborda el tema del paso de lo homogéneo a lo heterogéneo en la ciudad que existía a fines del siglo XIX y escribe un capítulo titulado "La heterogeneidad de la trama urbana", atribuyendo esta característica a los diversos orígenes de los habitantes y sus correspondientes particularidades arquitectónicas que definieron 
los perfiles acentuando las diferenciaciones. Años después la misma ratifica estos pensamientos refiriéndose al paisaje de la ciudad de Córdoba a fines del 1800 de la siguiente manera: "la uniformidad de Córdoba colonial de casas de techos de teja, se rompía cotidianamente con la nueva tipología proveniente de otras escuelas arquitectónicas trasladada por profesionales inmigrantes o en algunos casos, argentinos formados en Europa. Nuevos conceptos e imaginarios se incorporaban, mientras que desconocidos elementos constructivos, como el hierro y el acero, permitían innovar en obras viales y edilicias". (BOIXADÓS, Córdoba fotografiada entre 1870 y 1930. Imágenes urbanas, 2008)

Cesar Naselli también se refiere a la forma heterogénea del tejido edilicio de nuestra ciudad, pero del actual, relacionándolo con la cuadricula fundacional y su capacidad de proporcionar un orden cartesiano bidimensional que admite "diversas" propuestas formales en sus tres dimensiones." (NASELLI C. , Síntesis conceptual, 2013):

"Mirada como esquema morfológico-geométrico, la cuadrícula es la ley basada en el ángulo recto que dispone figuras cuadrangulares y de lados paralelos rectos (cuadrados y rectángulos, excepcionalmente triángulos rectángulos), ortogonales a la calle (línea de traza). En general no permite otras figuras puesto que procede por subdivisión interna paralela a sus lados. Es una ley definidamente bidimensional y horizontal, sobre el suelo o paralela al mismo. No es una ley tridimensional.

En lo vertical si bien imprime una suerte de aplicación de líneas verticales y horizontales, no define un volumen tridimensional. La tridimensionalidad se crea a partir de otras fuerzas (perfil urbano, volúmenes, composición del todo, normativas municipales, valor de la tierra, excepciones a la norma, especulación inmobiliaria, propiedad y medianería, espíritu individualista sobre las tradiciones de propietarios y proyectistas, etc.). También influyen notablemente la idea de modernidad asimilada a lo nuevo y esto a lo distinto, impactante y de moda; la idea de una modernidad asimilada a lo nuevo y a esto a lo distinto, impactante y de moda; la idea de una imagen moderna reñida con los valores de identidad tradicional y una escasa conciencia del paisaje urbano que hace preferir imágenes urbanas referidas a áreas centrales de las ciudades angloamericanas. También las teorías de diseño urbano divididas entre el contextualismo y la independencia creativa sin condicionamientos, sobre una imagen subyacente de la ciudad ideal del Movimiento Moderno, ponen lo suyo a esta conformación

La ausencia de arquetipos edilicios formales y tradicionales y la súbita desvalorización causada por el Movimiento Moderno, del único que acompañó históricamente a la cuadrícula desde el siglo XVI hasta los albores del siglo XX (casa patio y casa chorizo), hace que este sistema bidimensional, en cierta manera, admita toda propuesta formal y diversa.

Esta aceptación de lo diverso tiene un aspecto positivo: hace a la cuadrícula adaptable a la superposición de capas de trazas y de tramas de diversa escala y configuración con puntos fijos de interconexión verticales, cualidad especialmente apta para resolver las distintas escalas de observación del proyecto

Si miramos a nuestras ciudades desde la idea clásica veremos a la textura dinámica de las urbes latinoamericanas como una irregularidad no deseable que tenemos que disciplinar. Una opción alternativa es ver a esta textura como una característica propia desde la cual podemos accionar. (PARIS, La regularidad irregular, 2012)

\section{Hacia la construcción de nuevos mapas rugosos}

Por lo expuesto, entendemos que es posible analizar la conformación de la imagen urbana de hoy a partir de entender los procesos que consideramos estructurantes y definitorios de esta imagen urbana fragmentada y diversa:
a- El proceso de subdivisión del Parcelario
b- El proceso de conformación del Tejido edilicio
c- Los procesos marcados por Ordenanzas 

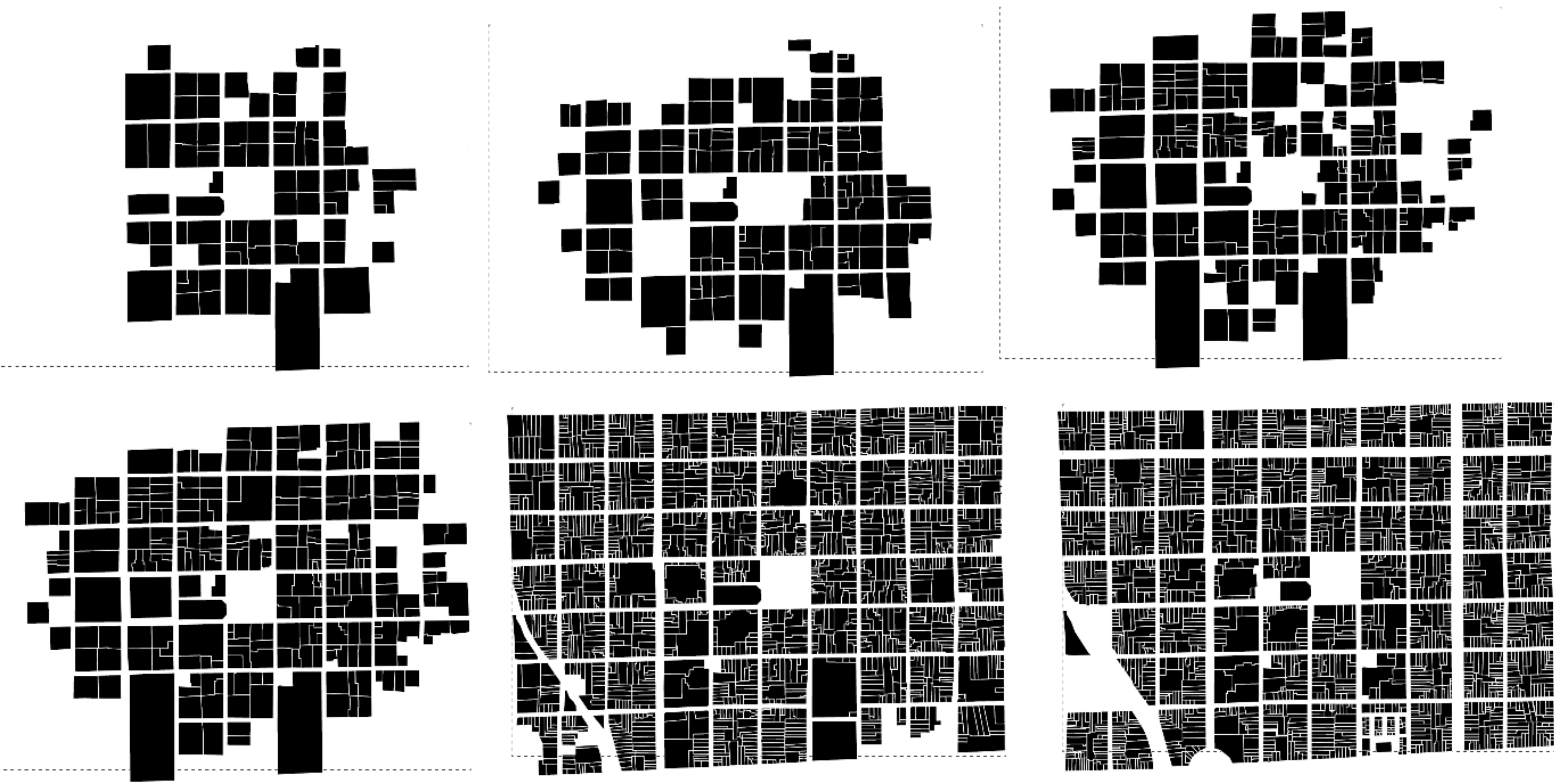

Proceso de subdivisión parcelario de las 70 manzanas fundacionales de la ciudad de Córdoba. Lotes ocupados en los años 1600-1650-1700-1810-1889-2016. De figuras pregnantes y relativamente homogéneas en cuanto a formas y medidas a la multiplicidad de formas y tamaños. Elaboración propia. Dibujo y redibujo en base a diferentes fuentes consultadas. Síntesis de lo presentado en SIIU 2015.

Habiendo analizado en una etapa previa, mediante la construcción y el redibujo de piezas técnicas, el proceso de fraccionamiento parcelario de las 70 manzanas fundacionales de la ciudad de Córdoba, desde la fundación hasta nuestros días haciendo cortes temporales con el objetivo de obtener indicios de su influencia en la conformación de la imagen urbana heterogénea y diversa de hoy, (PARIS, El proceso de subdivisión parcelaria y la configuración de la imagen heterogénea de la ciudad latinoamericana. Caso de estudio: ciudad de Córdoba, Argentina., 2015) vemos necesario ahora enfocarnos en la configuración morfológica de la masa edilicia que toma forma tridimensional teniendo como soporte a las parcelas e interaccionando con las ordenanzas vigentes.

En una primera instancia procedimos a redibujar la información existente y crear nuevas en los casos que no existían cruzando diferentes fuentes de información. Los estudios sobre los orígenes del ensanche de BarceIona (COROMINAS I AYALA, 2002) se constituyó en un antecedente metodológico en cuanto a formas de organizar la información y analizarla. Por otro lado es fundamental aclarar que el insumo de información para poder realizar las piezas técnicas (tanto bi como tridimensionales) para este estudio investigativo en relación a la forma del tejido edilicio en relación a las parcelas que lo contienen está dado principalmente por la información que brindan los estudios realizados anteriormente por las arquitectas Floglia y Goytia, (FOGLIA, GOYTIA, \& otros, La cuadrícula en el desarrollo de la ciudad hispanoamericana: caso Córdoba. 1573-1810., 1987), los registros sistematizados y las descripciones documentadas por el abogado Luque Colombres (LUQUE COLOMBRES, 1980) y las apreciaciones de la historiadora Boixados (BOIXADÓS, La heterogeneidad de la trama urbana, 2000)

El resultado es una nueva documentación elaborada por inferencias y que tiene el objetivo de convertirse en visualización de carácter orientativo que permite comprender el proceso de cambios del tejido edilicio y su relación con la rugosidad actual del mismo. De esta manera quedan definidos plantas, axonometrías y perspectivas a vuelo de pájaro del crecimiento y consolidación del tejido edilicio de los siguientes periodos: 1600, $1700,1810,1889$ y 2016. Los tres primeros periodos están armados por inferencias y deducciones de distintas fuentes ya que no se cuenta con información de los edificios existentes, salvos de algunas órdenes religiosas que si han permitido tener detalles precisos de lo construido en esos periodos. A partir de 1889 ya se cuenta con el catastro Machado y fotografías de la época que posibilitan un gran acercamiento con muchas certezas de la realidad del momento. Para el periodo actual, relevamiento in situ e información relevada de google earth permitieron obtener el modelo que refleja el tejido edilicio actual.

A continuación detallamos los insumos de información y los resultados a los que arribamos que permiten contar con nuevas piezas técnicas descriptivas de este proceso en cada periodo: 
Hasta finales del siglo XVII aproximadamente, las edificaciones de la ciudad de Córdoba se caracterizan por la precariedad de sus construcciones determinada por limitaciones económicas, de herramientas y la poca población. (FOGLIA, GOYTIA, \& otros, La cuadrícula en el desarrollo de la ciudad hispanoamericana: caso Córdoba. 1573-1810., 1987)

Desde el momento de la fundación se evidencia, a través de informes y órdenes del cabildo que constituyen una suerte de normas, una voluntad de delimitar la manzana con tapias o cercas de manera de definir el límite entre calle y parcelas. La repetición de las mismas en lapsos de 4 años entre ellas deja ver que, mínimamente, durante las primeras décadas la imagen de Córdoba era indefinida en términos geométricos euclidianos.

a- " “...se distribuyó solares entre pobladores mandando que se cercaren de dos tapias en alto ordinario dentro de dos años desde el día de la fecha, so pena perdidos dichos solares para que como vacíos se den a otras personas..." 1573, agosto. Informe de J. Luis de Cabrera.

b- "... los cuales dichos solares doy por servidos a los vecinos moradores; mando que los cerquen de la fecha de esta dos años primero siguientes so pena de veinte pesos de oro..." 1577

c- "... cercar los solares que dan sobre la plaza para defenderse de los naturales..." 1581, enero. Ordenanza del Cabildo.

Según Floglia y Goytia "Estas intenciones se concretan como se verificó, de manera muy aislada, predominando la ausencia de tapias aun en las proximidades de la plaza mayor" y agregan que los tipos arquitectónicos de esta etapa, se consolidaban de manera precaria por sus características técnicas constructivas y ubicados de manera aislada de los límites de cada lote sin una directa relación con la calle, lo que sumado a la no materialización del límite entre lo público privado da una línea municipal (hablando en términos actuales) discontinua.

En el caso de la tipología vivienda, las autoras tipifican 3 formas de ocupación en la parcela. En la mayoría de los casos se trata de: a- un volumen retirado de la calle y de los demás límites del lote. En algunos casos con tapias y con una relación indirecta con la calle. Los otras dos formas de ocupación en cuanto a vivienda se refiere se definen de la siguiente manera: $b$ - vivienda a la calle, con zaguán como nexo para la relación interior-exterior y c- viviendas retirada de los límites de la parcela pero con tiendas a la calle, este último ubicado frecuentemente en las esquinas y en las proximidades de la plaza mayor. Y establecen según sus deducciones que el tipo predominante en ese momento es el primer caso en excepción a algunas zonas cercanas a la plaza mayor donde aparecen los otros dos tipos arquitectónicos. (FOGLIA, GOYTIA, \& otros, 1987)

Por otro lado complementa esta información (fuente también consultada por Floglia y Goytia) los siguientes textos descriptivos de Luque Colombres: "con frecuencia, la puerta de entrada se abría en el cerco y comunicaba directamente con el patio sin zaguán de acceso. Cuando este existía, las habitaciones externas que lo flanqueaban solían destinarse a tiendas con entrada independiente y constituían unidades autónomas desde el puno de vista funcional aunque anexas a la estructura general del edificio..." según describe (LUQUE COLOMBRES, 1980).

2: Antovio SuÁrez Mejín. - Véase G-V-3.

Título: Merced a Francisco de Iloyos, 1577; lo adq. Pedro Satorque (?), quien lo vendió al cap. Antón Berrú antes del 11-IX-1578 (leg. 2, exp. 5). A su fall. se remató y lo compró Andrés Mejía a 30 ps. en ropa de algodón. El tte. de gob. dispuso que el precio so pagara en ropa, lienzo, calcetas, alpargatas y algodón, pero en esta tierra no había sino lienzo, por lo que autorizó el pago en esa moneda, 2-II-1584 (leg. 2, exp. 5). Ya para el 10-X-1595 el solar pertenecía a' Antonio Suárez Mejía (leg. 8, f. 109). Descripción: Baldío (ibíd. y leg. 57, exp. 1).

Manzana FVII, año 1600. Página 70. (LUQUE COLOMBRES, 1980) 
Del análisis de las fuentes bibliográficas mencionadas surgen como resultado las siguientes piezas técnicas que reflejan el estado del tejido edilicio en este periodo:

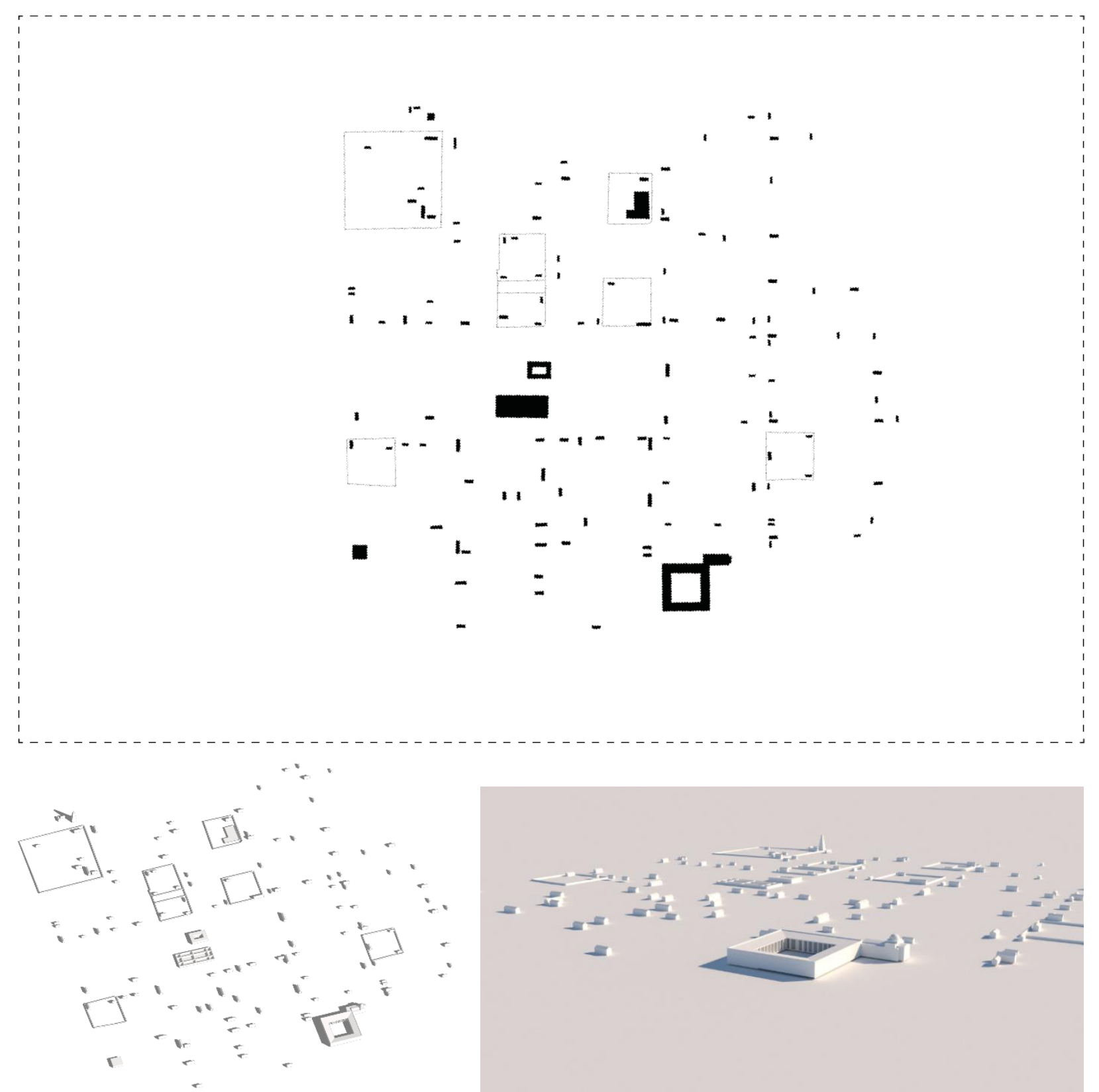

Año 1600. Estado de consolidación del tejido edilicio dentro de las 70 manzanas fundacionales de Córdoba. Planta, axonometría y vista a vuelo de pájaro. Imágenes de elaboración propia. 

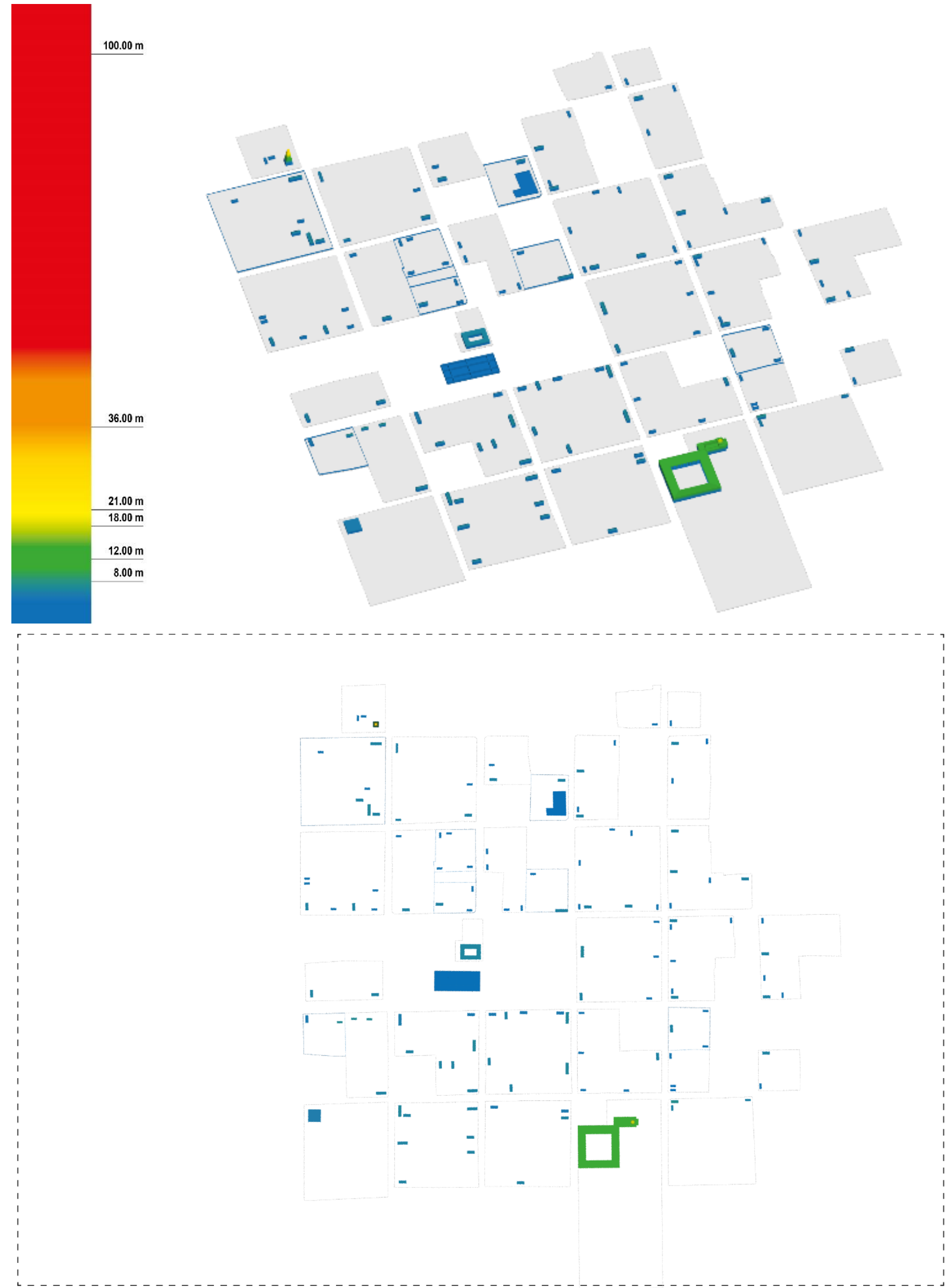

Año 1600. Axonometría y planta térmica de alturas. La escala va de 0 a 110 que es el edificio más alto en la actualidad (Torre Ángela) y los saltos graduales responden a las alturas de la ordenanza actual para el sector de estudio. Técnica, definición de malla térmica y aplicación sobre modelo tridimensional. Elaboración propia. 
Observaciones sobre las piezas y análisis elaborados:

Se trata de un tejido discontinuo, insipiente, asimilable a un tejido rural por la poca densidad edilicia y la falta de configuración de los límites de parcelas y consecuentemente de las manzanas.

En el periodo que va desde la fundación hasta 1600, la mancha urbana definida en este caso por los lotes ocupados, es de 30 manzanas de las 70 (escala macro de incompletitud) y en torno a la plaza central. El elemento regulador de la consolidación y crecimiento de las 70 manzanas de la ciudad de Córdoba se da a partir de un polo de crecimiento definido en este caso por la plaza central. (PANERAI \& Jean Charles DEPAULE, 1983)

Una sola manzana (la del convento San Francisco) llega hasta el borde sur del perímetro del rectángulo de las 70 manzanas.

Esto implica que la mancha no tiene en este momento la forma geométrica rectangular de carácter pregnante planteada lo que lleva a observar un primer nivel de rugosidad en su contorno y encontrándose una diferencia entre lo ideal planificado y lo real consolidado. La figura se expresa de manera irregular. De la figura rectangular de 4 lados pasamos a una figura de 15 lados.

La figura pregnante rectangular de proporciones solo se concreta en el plano de las ideas.

Al mismo tiempo, de estas 30 manzanas (una es la plaza central) 14 se encuentran ocupadas de manera completa y 16 incompletas lo que hace que más del $50 \%$ de las manzanas se desdibujen como tales y añadan un segundo nivel de rugosidad dado por la falta de ocupación. De la figura rectangular de 4 lados pasamos a una figura de 41 lados, derivado de un grano de rugosidad más pequeño.

Al no estar consolidados los bordes de las parcelas, los límites entre público y privado y entre parcelas entre si se desdibujan. La unidad manzana se presenta de manera irregular en sus límites en relación a la calle.

El mapa térmico permite visualizar la homogeneidad de alturas y el grano disperso.

\section{0}

Las descripciones de las construcciones existentes que están en el libro Orígenes históricos de la propiedad urbana de Córdoba. Siglos XVI y XVII (LUQUE COLOMBRES, 1980) junto a las descripciones graficas de Floglia y Goytia de los tipos urbanos arquitectónicos correspondientes a los periodos: "T.U.A. I, la repetición de tipos arquitectónicos semejantes, de factura simple, alineados sobre la traza viaria, siguiendo un orden regular y configurando un corredor unitario. Este tipo constituyo el componente consolidador del tejido del núcleo central. T.U.A. II, la repetición irregular de volúmenes edilicios de factura simple, ubicados sobre la trama regular, que en su relación con el trazado varia siguiendo leyes diferentes al de la trama base. Tal tipo de relación entre la arquitectura y la subdivisión parcelaria dio lugar a una organización desordenada y ambigua del corredor. Puede ser considerado como tipo urbano-arquitectónico de transición y fue el componente común del tejido heterogéneo que se dio en el área periférica o en los sectores de estructura indefinida. T.U.A. III, la concreción de un tipo singular de factura significativa que se localizó en esquina y se relacionó a través de un atrio o plazoleta, de manera indirecta y regular, con el espacio de la vía. Este tipo marco de manera puntual el tejido consolidándose a fines del siglo XVIII, con la terminación de los conjuntos religiosos y usos conexos."

2: Pedro González Arredondo. - Véase 1675.

Título: Véase 1675.

Descripción: "una sala con 8 tirantes cubierta de teja con sus puer-

tas, y en el patio otro cuarto de 3 tirantes, todo viejo" (leg. 210, exp. 3).

Gravámenes: Censo al conv. de S. Francisco (leg. 105, f. s/n).

Sucesores: Al fall. de González Arredondo la prop. fue adjud. a su hija Da. Josefa, casada con Francisco de Barzola, 1702 (leg. 210, exp. 3). Estos y Diego de Quiñones (véase $n^{\circ} 1$ ), imposibilitados de pagar los 

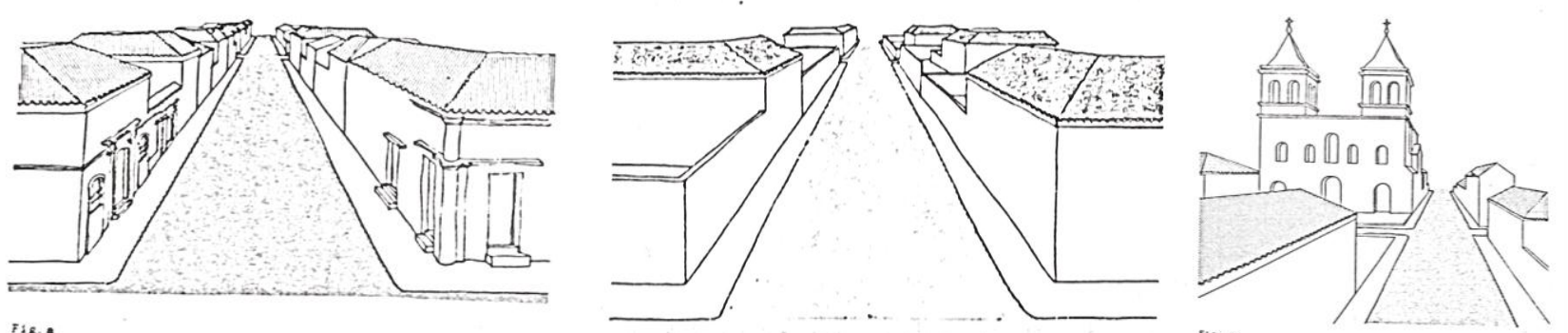

Diferentes Tipos urbanos arquitectónicos en la ciudad de Córdoba entre 1650 y 1750, T.U.A. Página 114 (FOGLIA, GOYTIA, \& otros, La cuadrícula en el desarrollo de la ciudad hispanoamericana: caso Córdoba. 1573-1810., 1987)

Del análisis de las fuentes bibliográficas mencionadas surgen como resultado las siguientes piezas técnicas que reflejan el estado del tejido edilicio en este periodo:
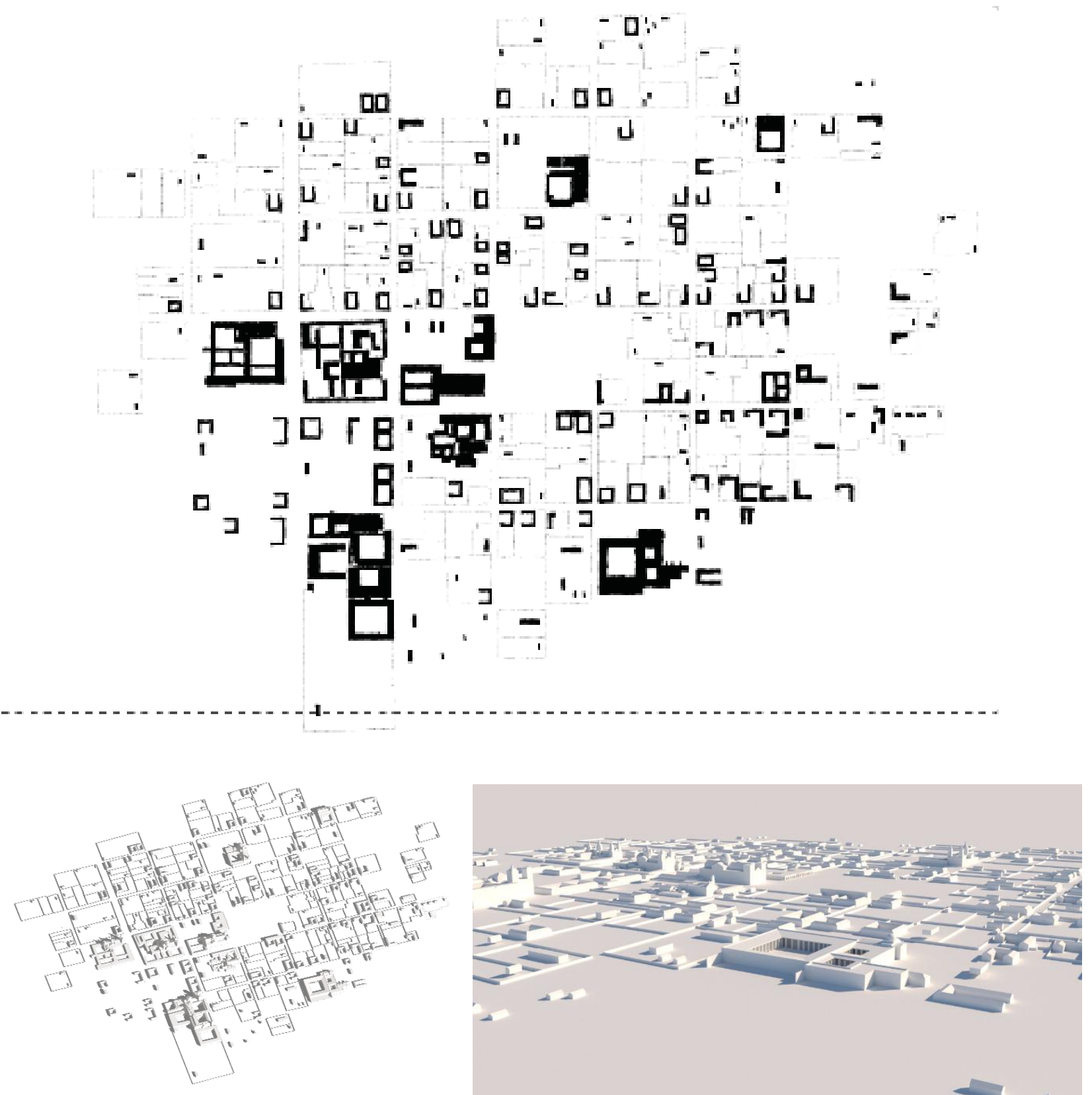

Año 1700. Estado de consolidación del tejido edilicio dentro de las 70 manzanas fundacionales de Córdoba. Planta, axonometría y vista a vuelo de pájaro. Imágenes de elaboración propia. 

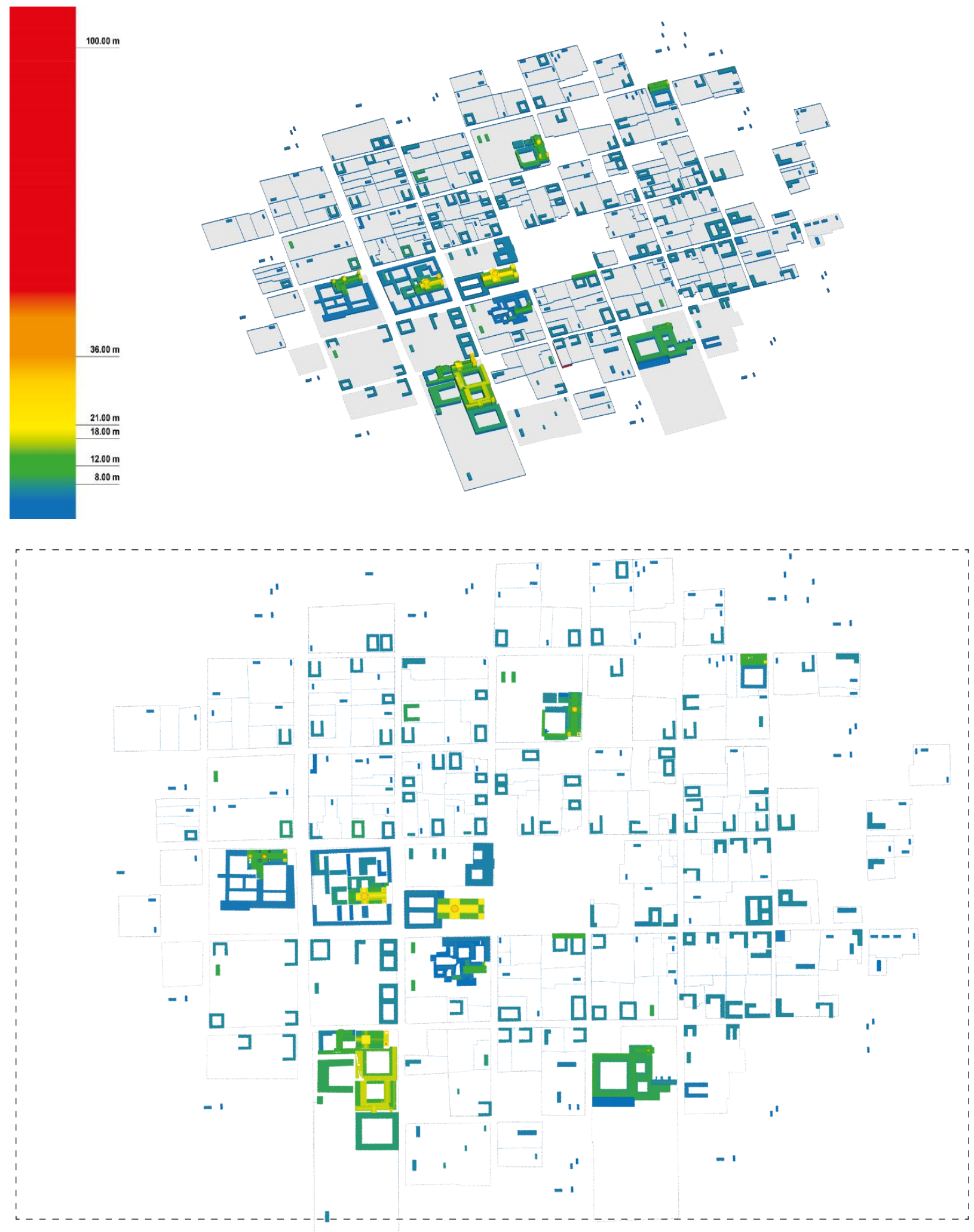

Año 1700. Axonometría y planta térmica de alturas. La escala va de 0 a 110 que es el edificio más alto en la actualidad (Torre Ángela) y los saltos graduales responden a las alturas de la ordenanza actual para el sector de estudio. Técnica, definición de malla térmica y aplicación sobre modelo tridimensional. Elaboración propia.

Observaciones sobre las piezas y análisis elaborados: 
El tejido sigue teniendo un carácter discontinuo de alturas homogéneas con las excepciones de algunos edificios religiosos que ya están construidos.

En el periodo que va desde 1600 a 1700, las manzanas ocupadas son 49 de las 70 . El crecimiento sigue siendo en anillos alrededor de la plaza central. 11 manzanas llegan hasta los bordes norte, sur y este del perímetro del rectángulo de las 70 manzanas. El borde oeste, que se encuentra más lejos del centro (porque la plaza central no se encuentra propiamente en el centro) no es alcanzado en este momento por la ocupación. De la figura rectangular de 4 lados pasamos a una figura de 41 lados.

Al mismo tiempo, de estas 49 manzanas ocupadas, 20 se encuentran ocupadas de manera completa y 29 incompletas lo que hace que el $60 \%$ de las manzanas se desdibujen como tales y continúen marcando un segundo nivel de rugosidad. De la figura rectangular de 4 lados pasamos a una figura de 63 lados, definiendo un grano de rugosidad más pequeño propio de los lados de los lotes.

En este periodo, los bordes de los lotes ya están definidos en la mayoría de los casos, de esta manera comienzan a quedar definidos los límites entre público y privado y entre parcelas entre si.

En cuanto al mapa térmico de alturas, y comparando con el periodo anterior es posible ver como surgen en la línea de cielo las torres de los edificios religiosos por sobre la masa homogénea.

\section{0}

En este periodo son fundamentales las descripciones graficas de Foglia y Goytia que construyen una imagen a vuelo de pájaro de elaboración propia en base a los tipos urbanos arquitectónicos detectados para este periodo: "la reactivación edilicia que se produjera como consecuencia del crecimiento económico y demográfico provoco la paulatina sustitución de las viviendas precarias iniciales, por otras construcciones de nueva factura". Por otro lado en relación a los tipos urbanos arquitectónicos constituyentes de este tejido, quedan definidos de la siguiente manera: "T.U.A. I, predominante por su cantidad y regular ubicación a lo largo de las vías, constituyendo el componente común y básico del tejido ya indicado generando una imagen simple y homogénea. T.U.A. II, desaparece en la medida que se consolida el TUA I en las 70 manzanas primigenias y reaparece en la zona oeste de ampliación de la planta urbana. T.U.A. III, emerge puntualmente en esquinas o en el centro de algunos tramos de vías, mojonando perimetralmente, por su localización, el núcleo central. Produce también una segmentación significativa de la longitud de la vía, al articular el espacio calle, con el atrio y la plazoleta. Constituye por su naturaleza diferente, singular y simbólica el elemento que enriqueció la regular simplicidad del tejido."

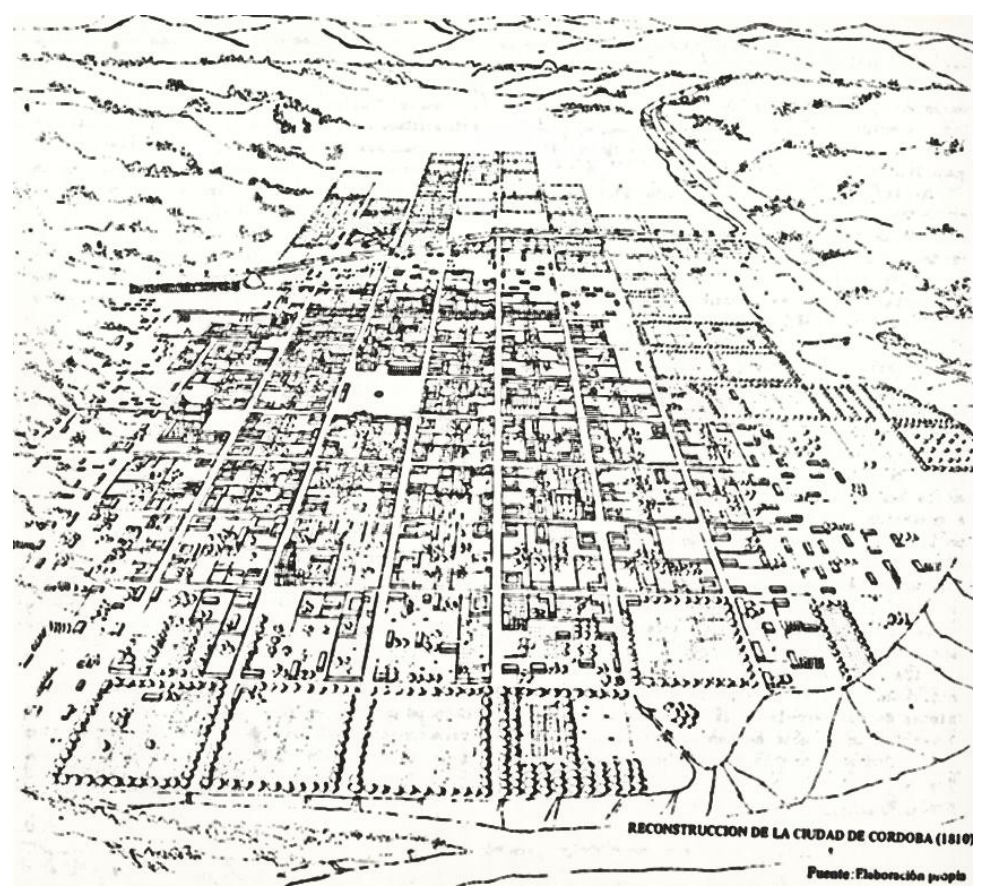


Reconstrucción de la ciudad de Córdoba hacia 1810, (FOGLIA, GOYTIA, \& otros, La cuadrícula en el desarrollo de la ciudad hispanoamericana: caso Córdoba. 1573-1810., 1987). Es posible observar el paso gradual de una conformación relativamente homogénea definida alrededor de la plaza central a una conformación con una mayor heterogeneidad y falta de uniformidad en los bordes de lo construido. En esta imagen se puede observar que los límites iniciales de las 70 manzanas fundacionales son sobrepasados por las construcciones al norte, este y oeste.

Del análisis de las fuentes bibliográficas mencionadas surgen como resultado las siguientes piezas técnicas que reflejan el estado del tejido edilicio en este periodo:
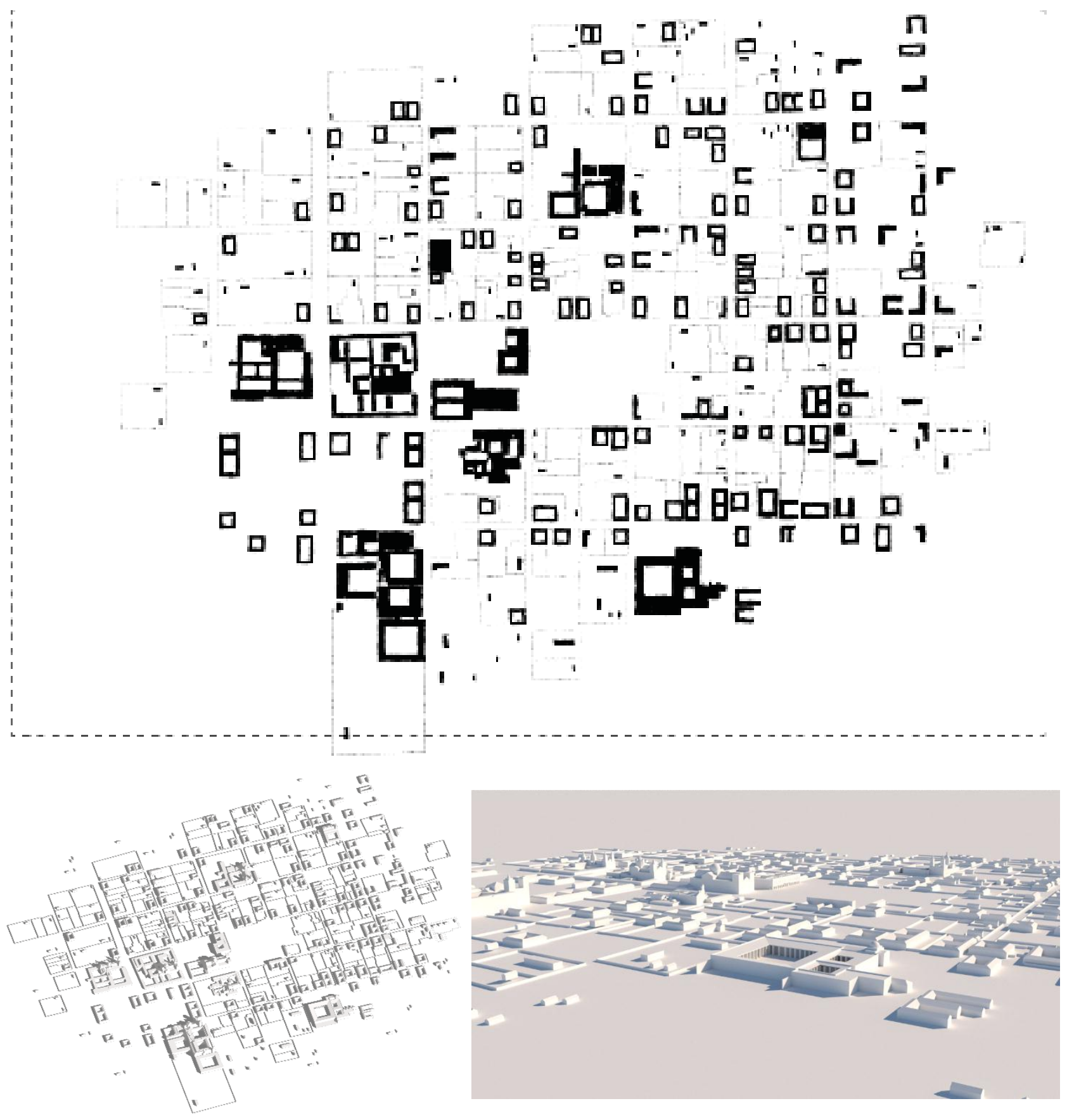

Año 1810. Estado de consolidación del tejido edilicio dentro de las 70 manzanas fundacionales de Córdoba. Planta, axonometría y vista a vuelo de pájaro. Imágenes de elaboración propia. 

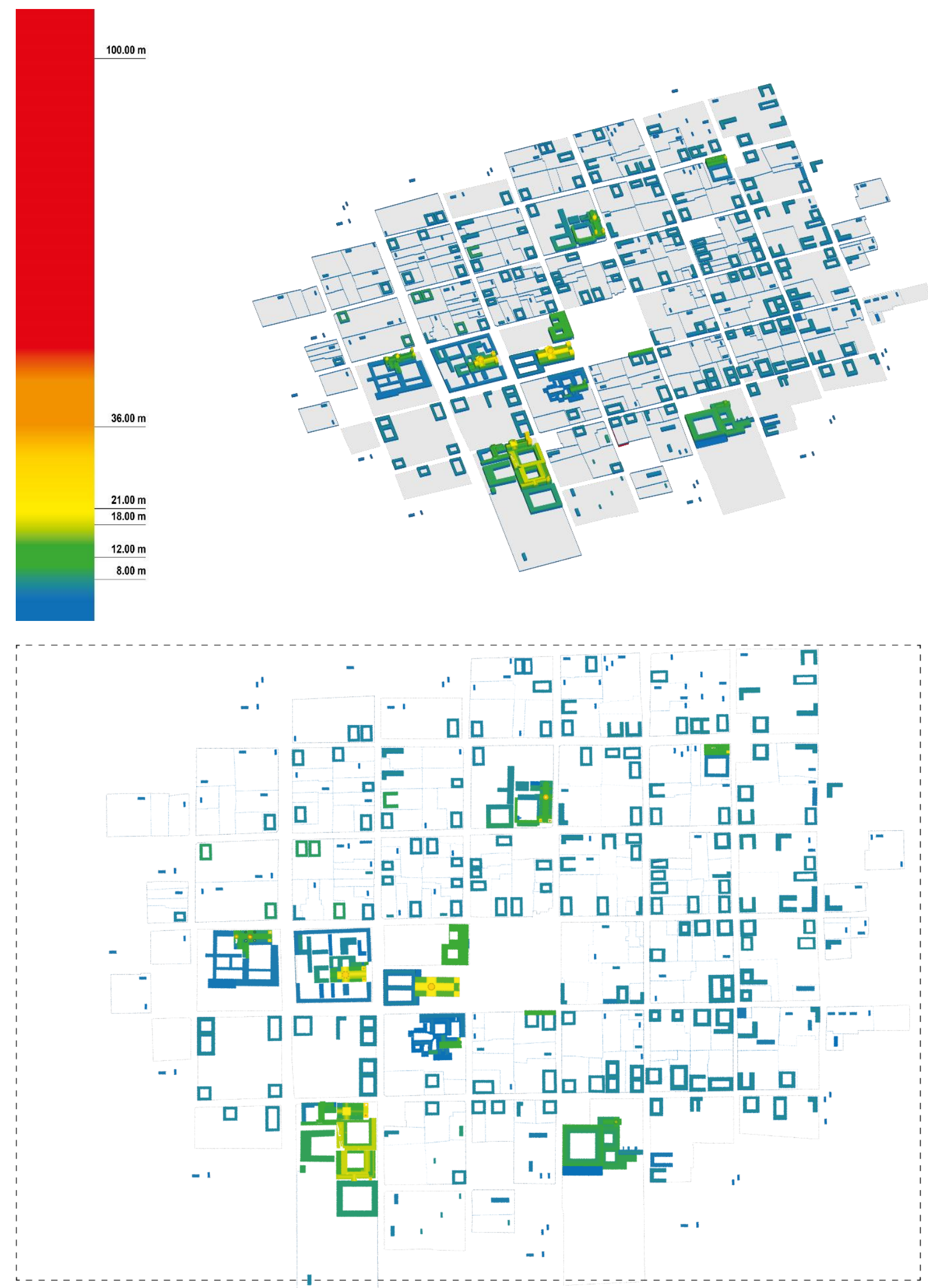

Año 1810. Axonometría y planta térmica de alturas. La escala va de 0 a 110 que es el edificio más alto en la actualidad (Torre Ángela) y los saltos graduales responden a las alturas de la ordenanza actual para el sector de estudio. Técnica, definición de malla térmica y aplicación sobre modelo tridimensional. Elaboración propia. 
Observaciones sobre las piezas y análisis elaborados:

En el periodo que va desde 1700 a 1810 las manzanas ocupadas son 52 de las 70 . El crecimiento sigue siendo en anillos alrededor de la plaza central. 14 manzanas llegan hasta los bordes norte, sur y este del perímetro del rectángulo de las 70 manzanas. El borde oeste, que se encuentra más lejos del centro continúa sin ser alcanzado, cabe destacar que hacia el oeste se encuentra el Arroyo de La Cañada.

De la figura rectangular de 4 lados pasamos a una figura de 16 lados.

Al mismo tiempo, de estas 52 manzanas ocupadas, 31 se encuentran ocupadas de manera completa y 21 incompletas lo que hace que el $40 \%$ de las manzanas se desdibujen como tales y continúen marcando un segundo nivel de rugosidad. De la figura rectangular de 4 lados pasamos a una figura de 52 lados, definiendo un grano de rugosidad más pequeño propio de los lados de los lotes.

En este periodo, los bordes de los lotes ya están materializados en la mayoría de los casos, de esta manera comienzan a quedar definidos los límites entre público y privado y entre parcelas entre sí.

\section{9}

En el libro Civilización y Barbarie, vida de Juan Facundo Quiroga, Domingo Faustino Sarmiento describe la llegada a la ciudad de Córdoba en la primera mitad del siglo XIX de la siguiente manera: "En verdad que el viajero que se acerca a Córdova busca i no encuentra en el horizonte la ciudad santa, la ciudad mística, la ciudad con capelo i borlas de doctor. Al fin, el arriero le dice: “Vea ahí..., abajo, entre los pastos...". I, en efecto, fijando la vista en el suelo, i a corta distancia, vense asomar una, dos, tres, diez cruces seguidas de cúpulas i torres de los muchos templos que decoran esta Pompeya de la España de la media edad." (SARMIENTO, 1845)

En este periodo contamos con el Catastro Machado (Archivo de la Municipalidad de Córdoba) donde están registradas cada una de las manzanas dela ciudad con sus edificios dibujados en planta.

Esto sumado a fotografías de la época provistas por el Archivo Fotográfico de Córdoba permite reconstruir los modelos en 3 dimensiones.

Siguen siendo utilizados los textos de Foglia y Goytia (FOGLIA, GOYTIA, \& otros, La cuadrícula en el desarrollo de la ciudad Hispanoamericana. El Caso de Córdoba. Tomo II., 1994) 


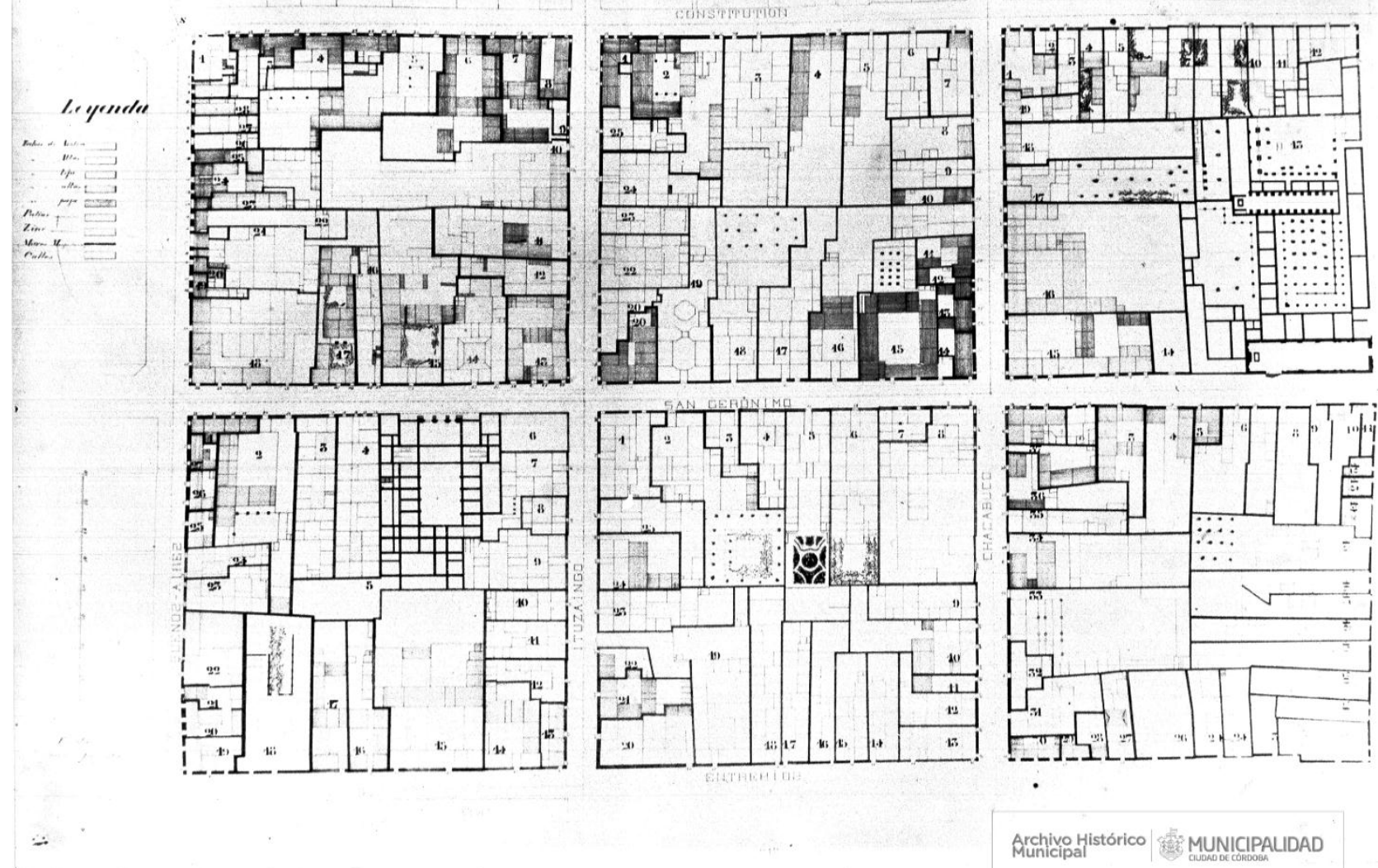

Fotografía Inventario 2358 (anverso), correspondiente a Plancha número 37 del Catastro Machado perteneciente a la Colección de Fotografías existente en el Archivo Histórico Municipal de la Ciudad de Córdoba Dr. Carlos Luque Colombres, Argentina.

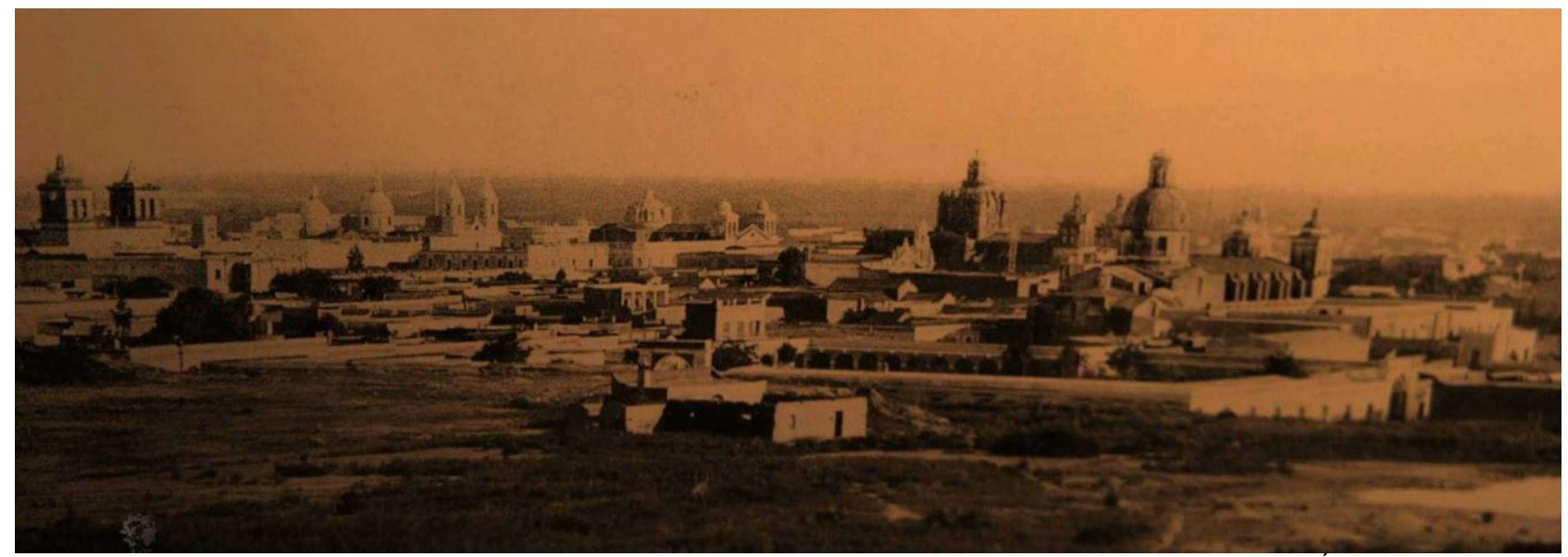

Vista hacia el centro histórico de la ciudad de Córdoba. Año de 1895. Archivo Fotográfico de Córdoba - Álbum de Estructuras edilicias - inventario: № 1994 (fragmento) Nota: En primer plano aparece la inmensa estructura con arcos y portal de medio punto, refiere al antiguo Mercado Sud. Imagen tomada desde la manzana ubicada entre las calles Buenos Aires, Bv Illia, Ituzaingó y Rondeau. 


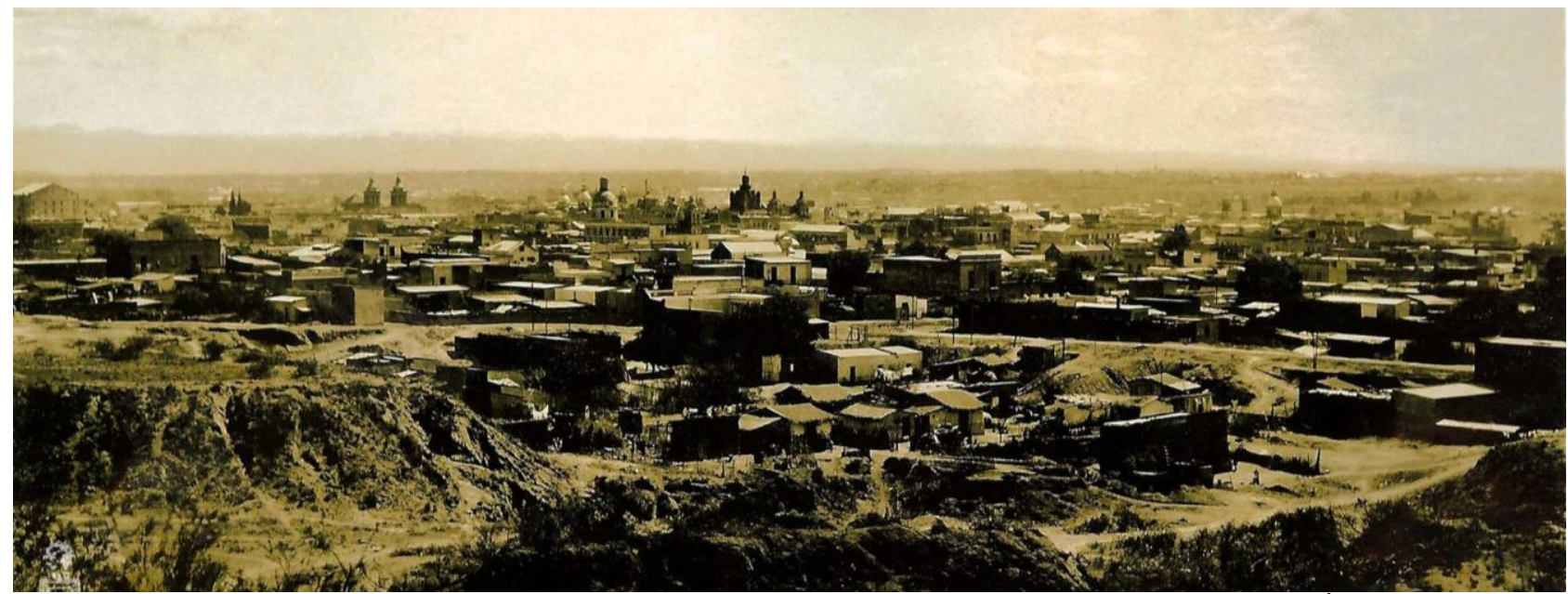

Vista de la ciudad de Córdoba. Década de 1930. Archivo Fotográfico de Córdoba - Documento Fotográfico - Álbum de Estructuras Edilicias - Inventario: № 2768 (fragmento). Nota: Tomada desde las barrancas sureste de la ciudad.

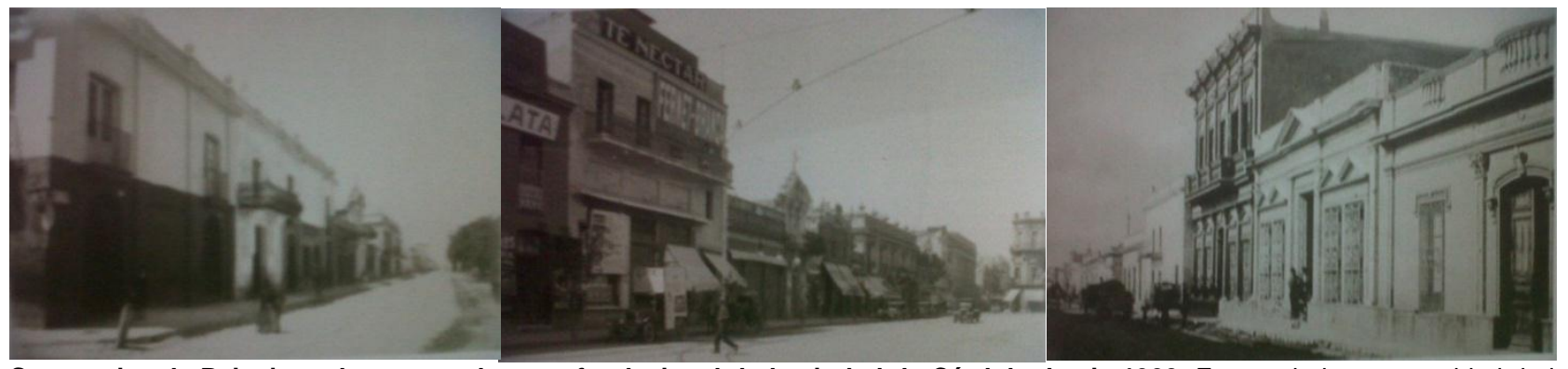

Secuencias de Paisajes urbanos en el casco fundacional de la ciudad de Córdoba hacia 1900. Fuente: la hererogeneidad de la trama urbana, (BOIXADÓS, 2008). Página 73.

Del análisis de las fuentes bibliográficas mencionadas surgen como resultado las siguientes piezas técnicas que reflejan el estado del tejido edilicio en este periodo:
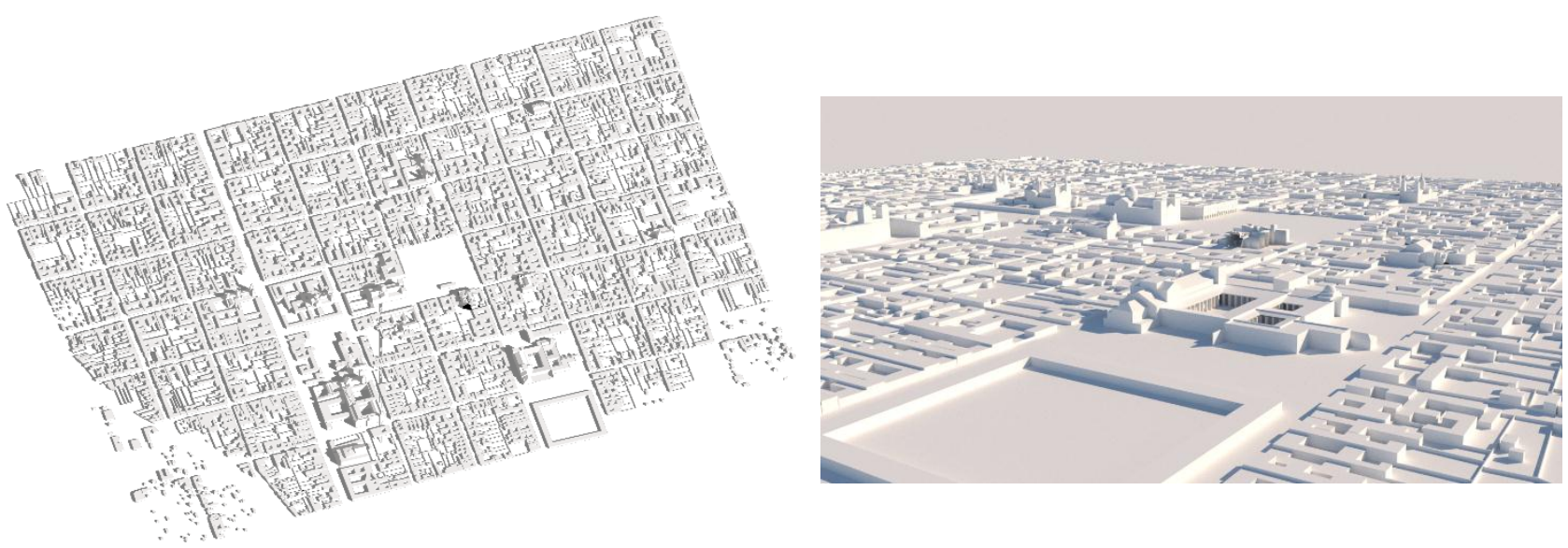


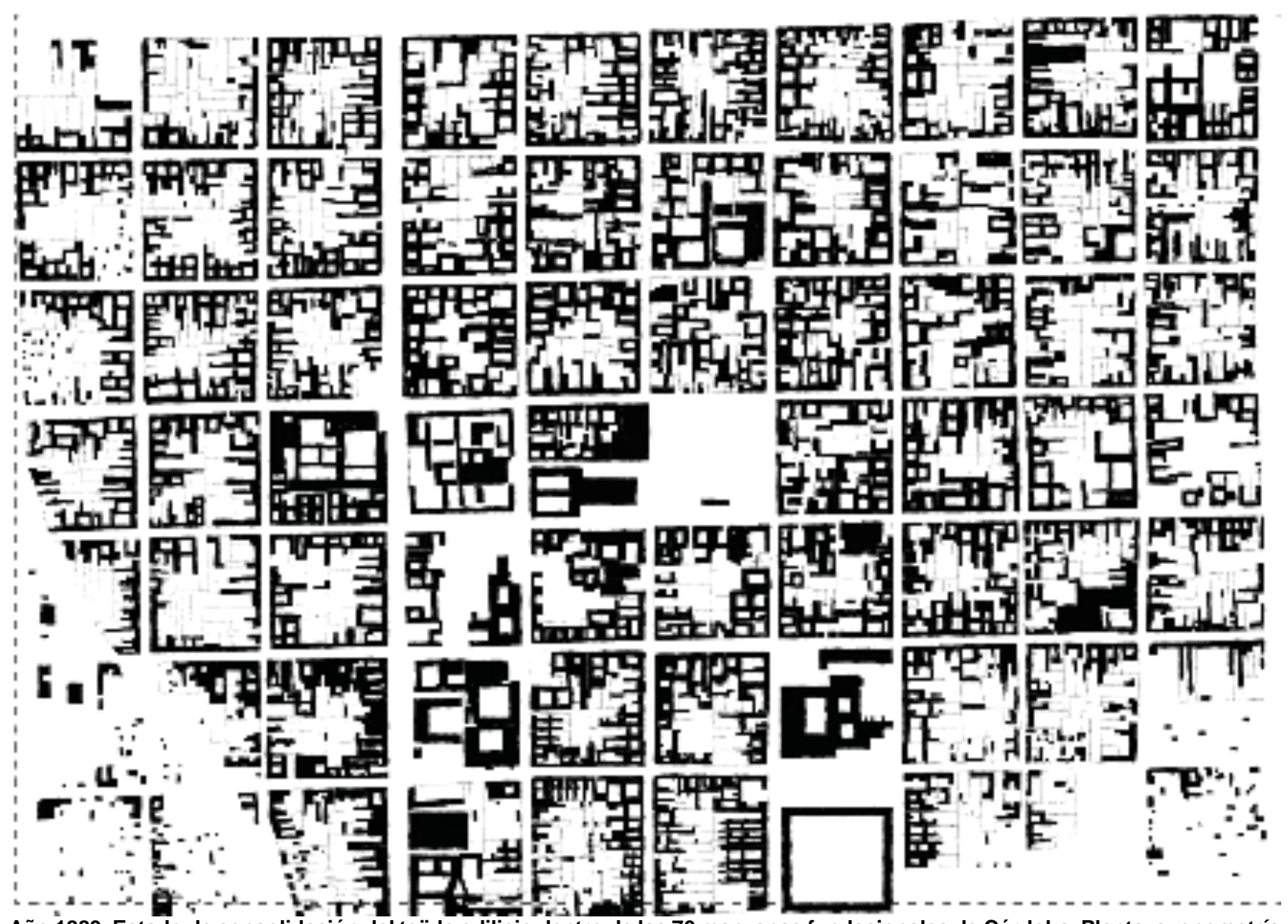

Año 1889. Estado de consolidación del tejido edilicio dentro de las 70 manzanas fundacionales de Córdoba. Planta, axonometría y vista a vuelo de pájaro. Imágenes de elaboración propia. 

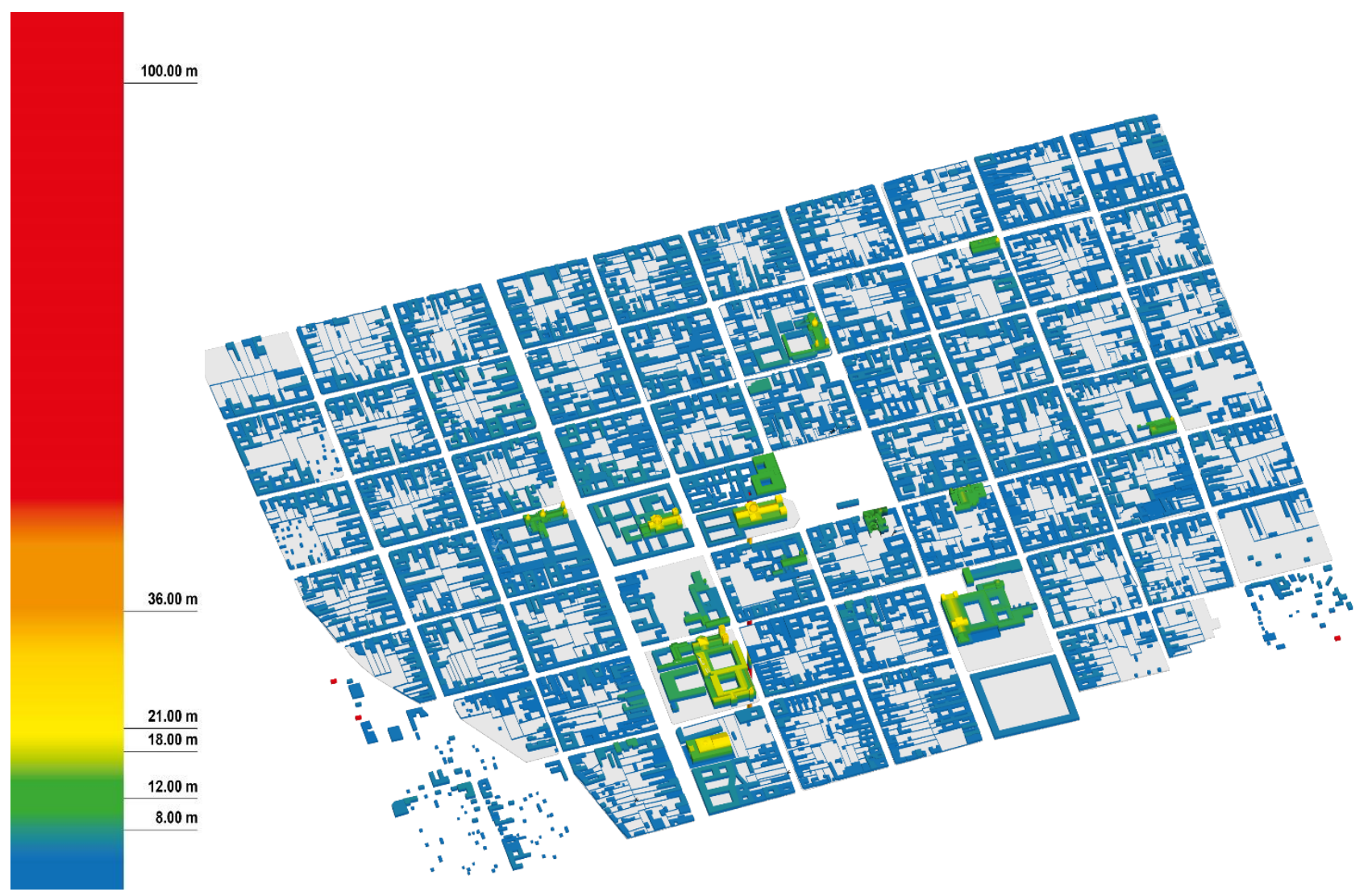

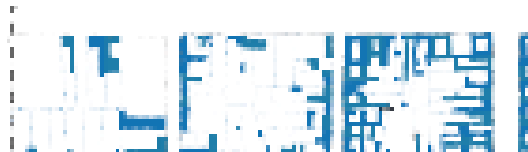

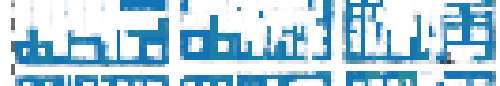
PPP :

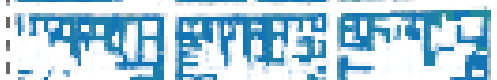

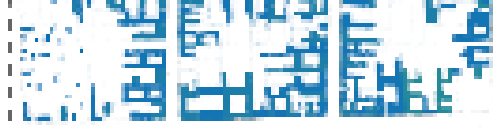

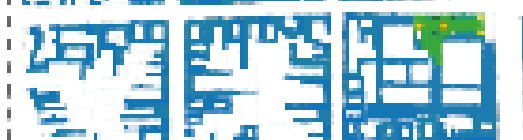

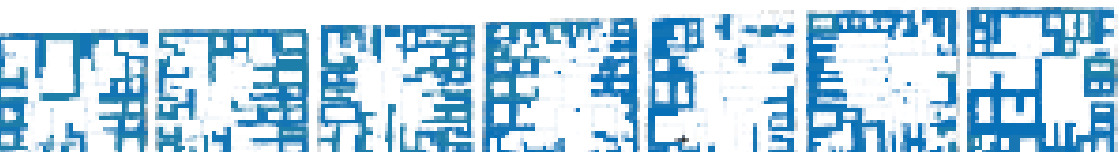

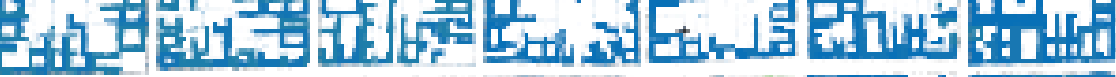

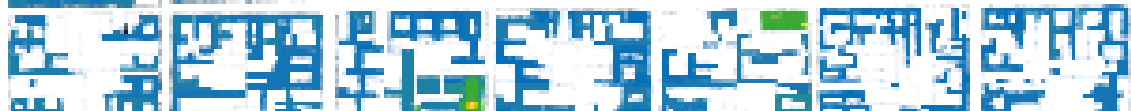

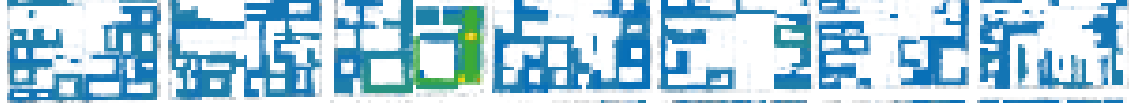

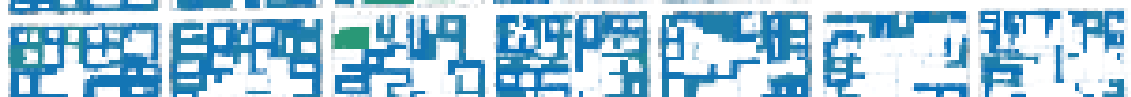
Fond

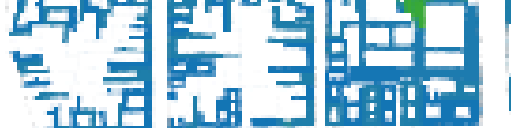

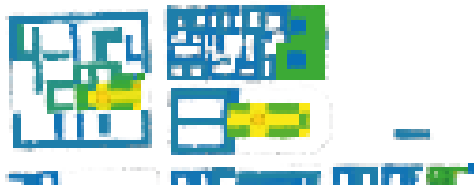
एक्षास जr4
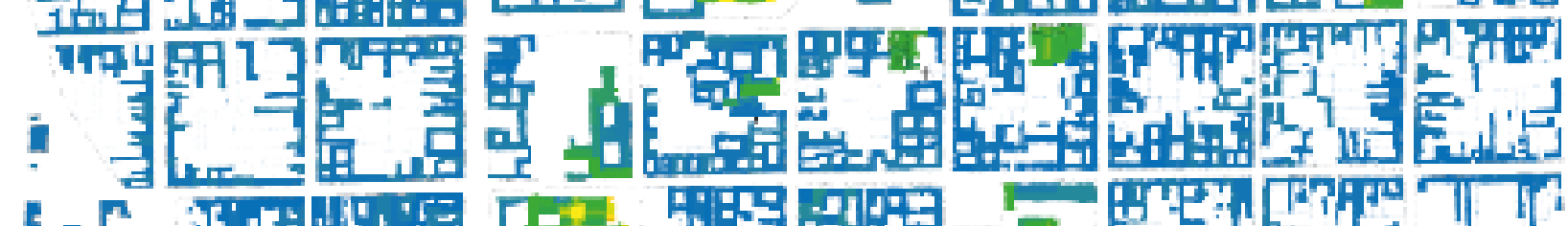

1 - 1 on

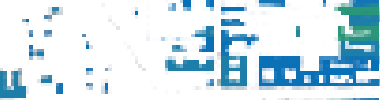

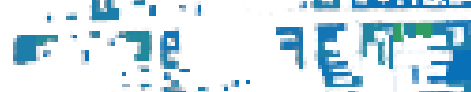

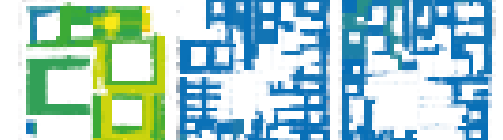
-

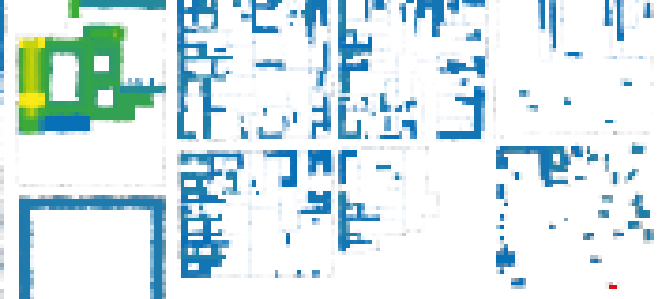

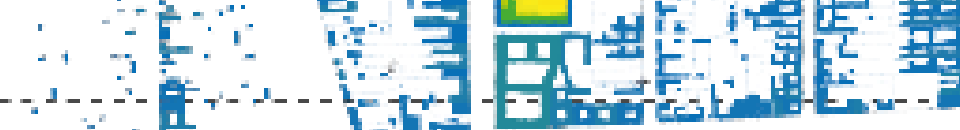

Año 1889. Axonometría y planta térmica de alturas. La escala va de 0 a 110 (que es el edificio más alto en la actualidad:Torre Ángela) y los saltos graduales responden a las alturas de la ordenanza actual para el sector de estudio. Técnica, definición de malla térmica y aplicación sobre modelo tridimensional. Elaboración propia. 
Del análisis de las fuentes bibliográficas mencionadas surgen como resultado las siguientes piezas técnicas que reflejan el estado del tejido edilicio en este periodo:

El tejido edilicio se ve esponjado, con un equilibrio entre llenos y vacíos. La tipología predominante tiene patios centrales y al fondo del lote y las edificaciones se agrupa en los bordes consolidando el límite entre lo público y lo privado.

En 1889 las 70 manzanas están ocupadas. El crecimiento sigue siendo en anillos alrededor de la plaza central. Los 4 bordes son alcanzados y sobrepasados. La figura rectangular de 4 lados se consolida y es sobrepasada, lo que lleva a desconfigurarla nuevamente, antes por no llegar a los límites, ahora por sobrepasarlos. Como consecuencia la pregnancia del rectángulo fundacional ya no es percibida.

Los obstáculos de crecimiento (Panerai) conformados por el curso de la cañada coincidente con el lado oeste y la barranca coincidente con el lado sur de las 70 manzanas, son superados.

De estas 70 manzanas, 64 se encuentran ocupadas de manera completa y solo 6 incompletas (9\%). Los lotes faltantes son muy escasos, igual, de la figura rectangular de 4 lados pasamos a una figura de 22 lados.

En este periodo, los bordes de los lotes ya están definidos en su totalidad, quedando definidos los límites entre público y privado y entre parcelas entre sí.

En cuanto al mapa térmico de alturas, los edificios que toman mayor presencia en este periodo son los religiosos, donde sus iglesias y conventos están desarrollados en extensión y altura.

\section{6}

En la actualidad contamos con información provista por la Municipalidad de Córdoba, google earth y el propio relevamiento realizado en el área central en los últimos años con el equipo de investigación y docencia de la Catedra de Diseño Urbano 2 de la Facultad de Arquitectura de la Universidad católica de Córdoba, el cual dirijo desde 2002.

Del análisis de las fuentes bibliográficas mencionadas surgen como resultado las siguientes piezas técnicas que reflejan el estado del tejido edilicio en este periodo:
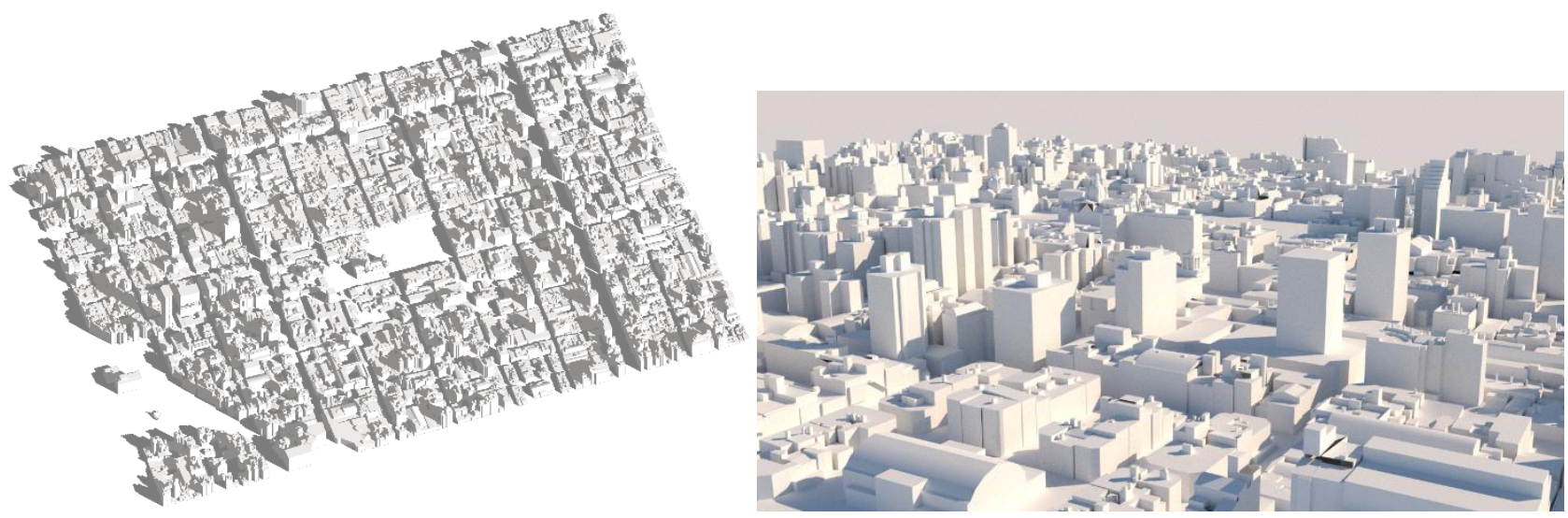


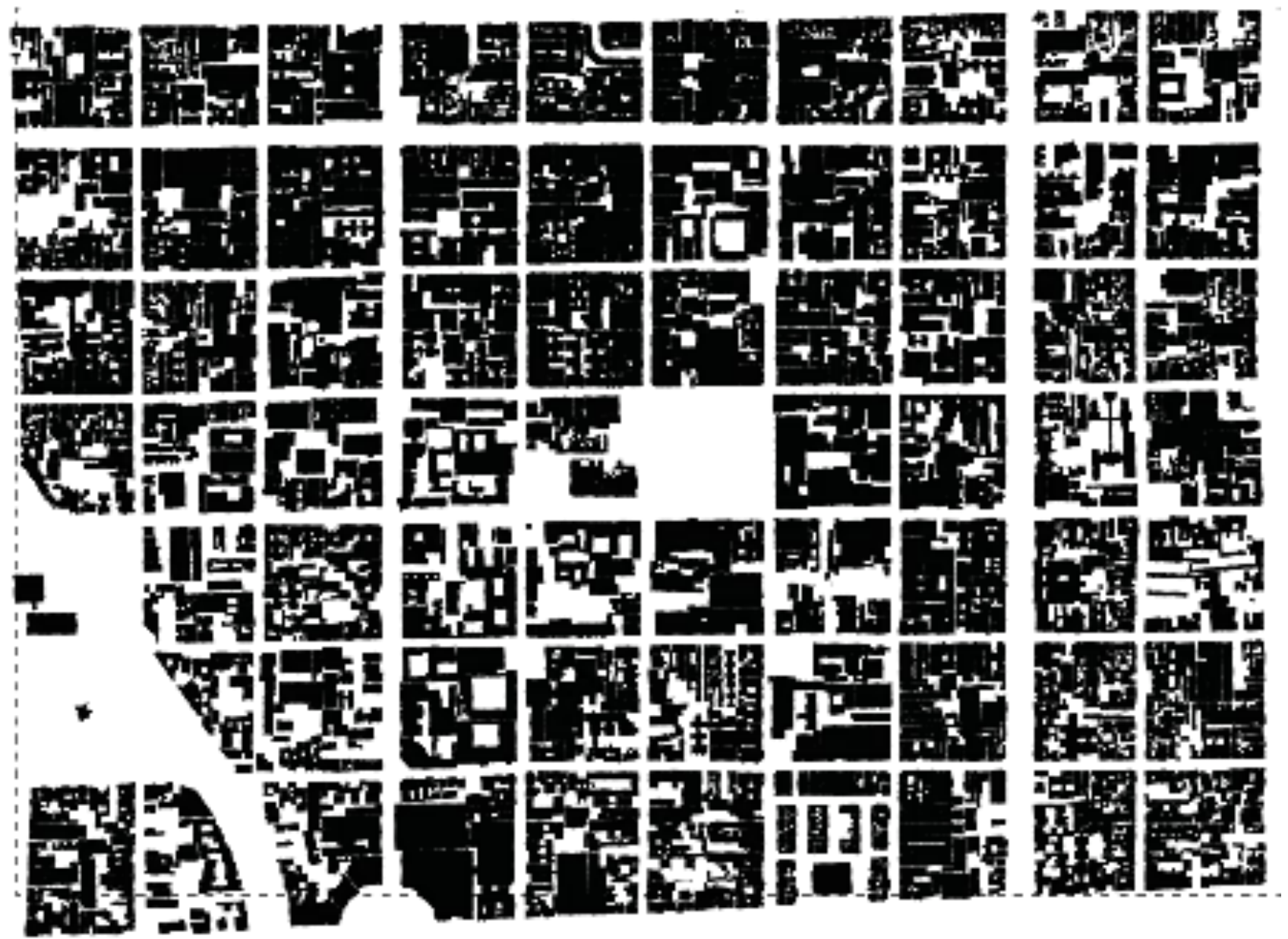

Año 2016. Estado de consolidación del tejido edilicio dentro de las 70 manzanas fundacionales de Córdoba. Planta, axonometría y vista a vuelo de pájaro. Imágenes de elaboración propia. 

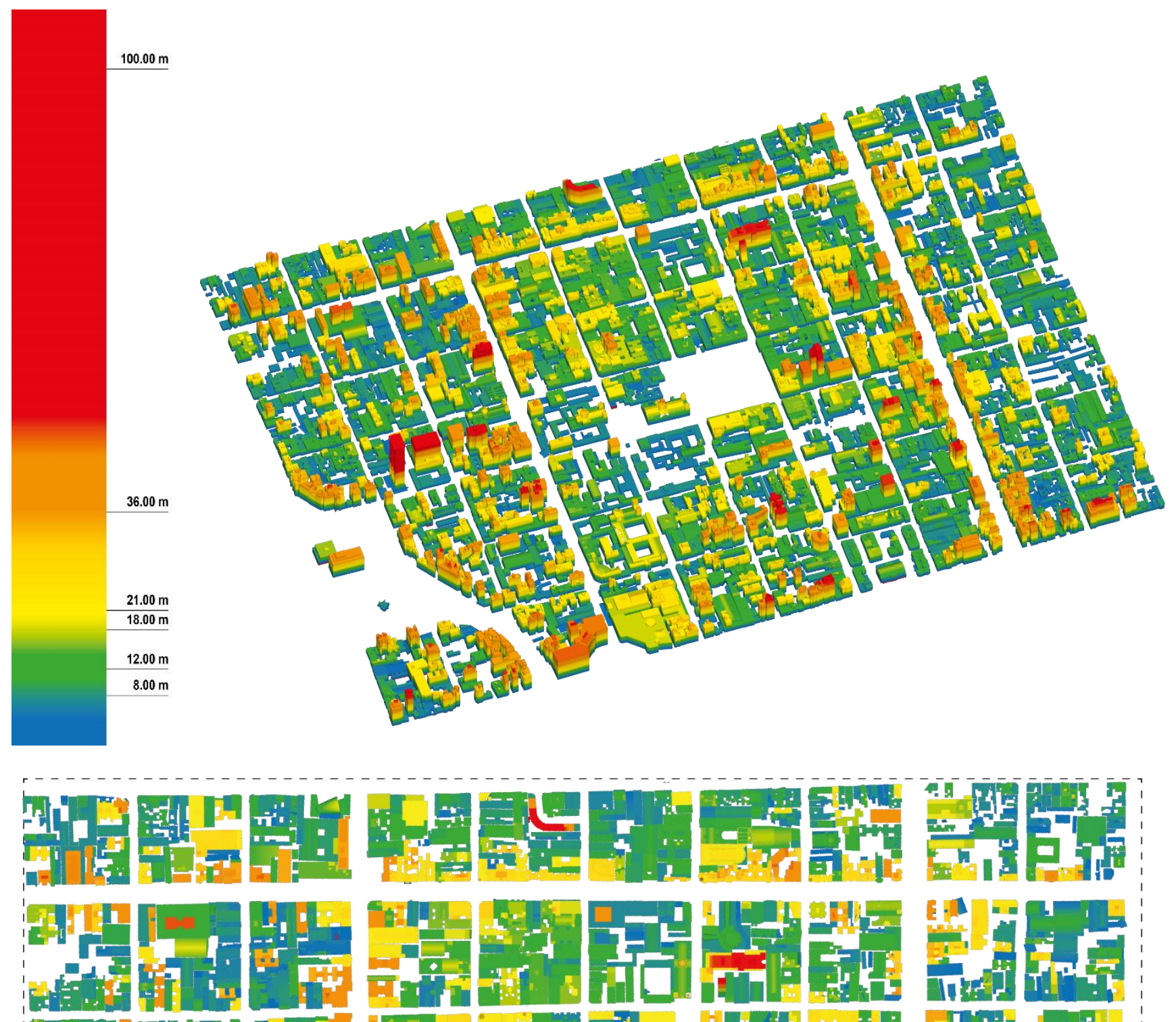

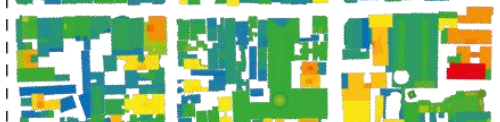
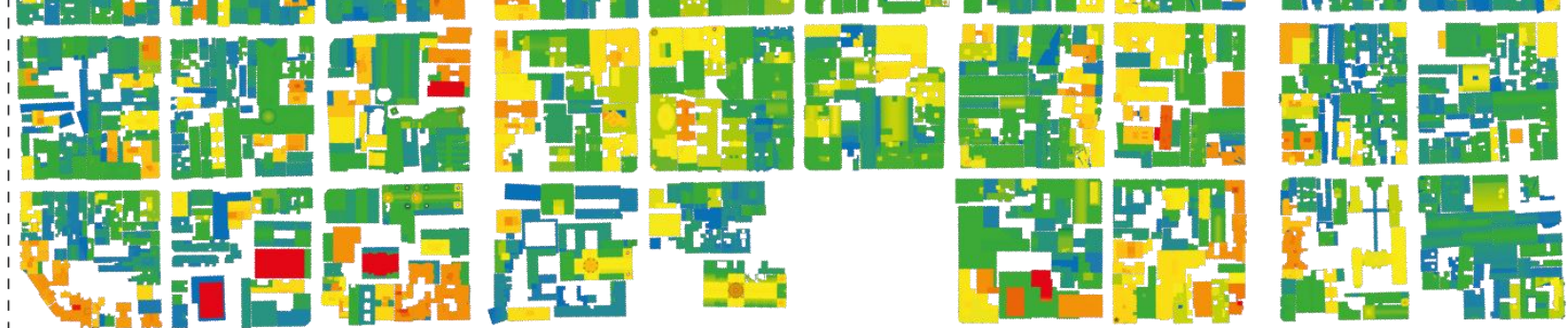

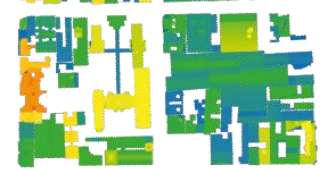
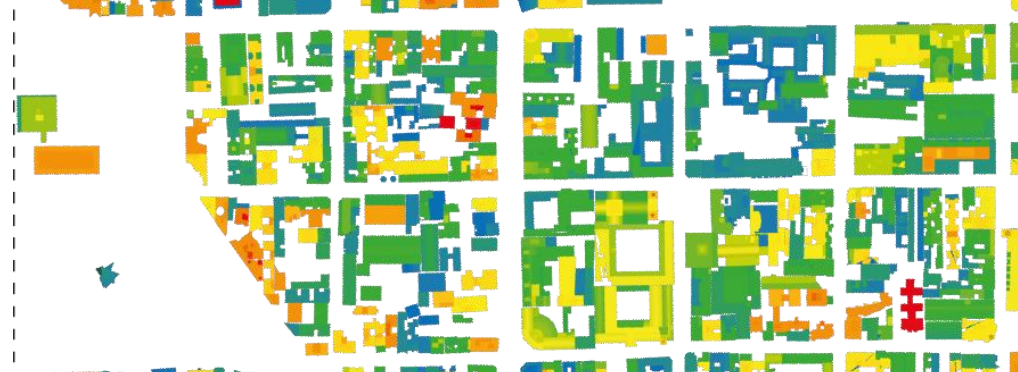

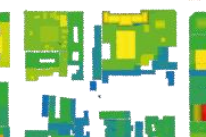
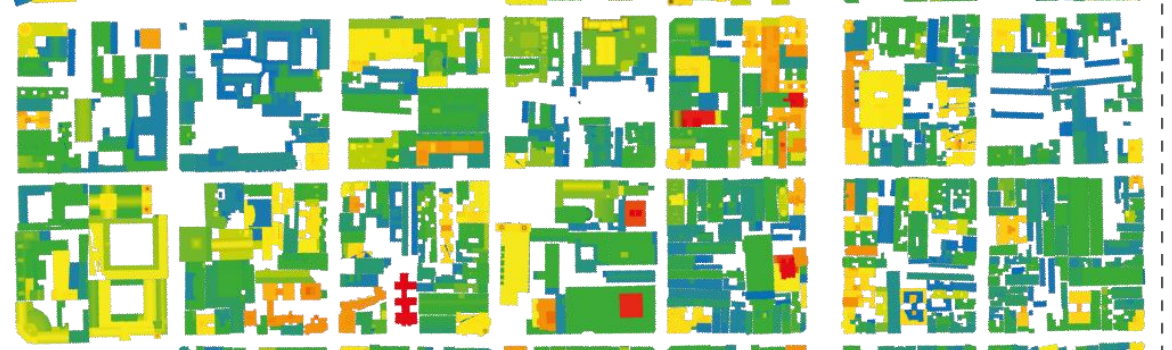

$21=9$
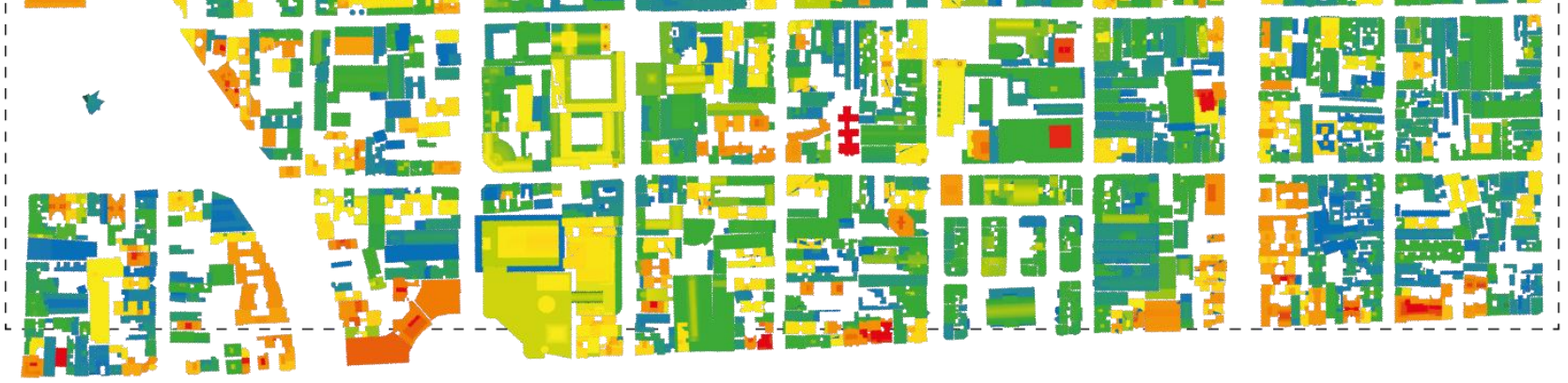

Año 2016. Axonometría y planta térmica de alturas. La escala va de 0 a 110 (que es el edificio más alto en la actualidad: Torre Ángela) y los saltos graduales responden a las alturas de la ordenanza actual para el sector de estudio. Técnica, definición de malla térmica y aplicación sobre modelo tridimensional. Elaboración propia. 
Del análisis de las fuentes bibliográficas mencionadas surgen como resultado las siguientes piezas técnicas que reflejan el estado del tejido edilicio en este periodo:

El tejido en primer lugar busca ocupar la totalidad del lote, materializando la tendencia que se veía en el periodo anterior, llegando a ocupar en algunos casos hasta el $100 \%$ de la superficie salvo en los predios donde existen edificios de valor patrimonial. En segundo lugar la masa edilicia se eleva llegando a alturas que En 2016 las manzanas ocupadas son las 70. Y la figura rectangular de 4 lados está consolidada y sobrepasada, como consecuencia la pregnancia del rectángulo fundacional ya no es percibida.

La totalidad de los lotes están ocupados. La figura rectangular de 4 lados pasamos a una figura de xx lados, definiendo un grano de rugosidad más pequeño propio de los lados de los lotes.

En este periodo, los bordes de los lotes ya están definidos en la mayoría de los casos, de esta manera comienzan a quedar definidos los límites entre público y privado y entre parcelas entre sí.

Merece una especial anterior el mapa térmico que expone por un lado la diversidad de alturas que otorgan una textura rugosa uniforme por lo variada y diversa.

Por otro lado el modelo expone la falta de adecuación de la realidad con las ordenanzas vigentes

A partir de la comparación de los mapas términos de cada periodo podemos mirar el proceso de trasformación del tejido edilicio dentro de las 70 manzanas fundacionales de la ciudad de Córdoba de la siguiente manera:

Hasta finales del siglo XVII aproximadamente, las edificaciones de la ciudad de Córdoba se caracterizan por la precariedad de sus construcciones determinada por limitaciones económicas, de herramientas y la poca población, por lo que en los periodos señalados como 1600 y 1700 la imagen urbana queda constituida con un grano edilicio disperso donde el límite entre lo público y lo privado es de carácter difuso (FOGLIA, GOYTIA, $\&$ otros, 1987). Con una altura predominante de una y excepcionalmente dos plantas. La sumatoria de estas características de llenos y vacíos con predominancia de estos últimos otorga una textura urbana esponjosa y homogénea donde la matriz (FORMAN \& otros, 1995) es el vacío por su conectividad y las edificaciones se presentan como parches aislados.

Esta textura predominantemente lisa, se podría percibir como algo alterada recién desde mediados de 1700 y ya claramente en el periodo señalado como 1810, por los volúmenes de los edificios de los templos religiosos que empiezan a sobresalir por comparación con su entorno inmediato conformado por una concatenación de baldíos y en algunos casos tapias.

En el periodo 1889, la ciudad ha crecido y se ha densificado, ingresan nuevos tipos arquitectónicos y tecnologías que definen nuevos modos de hacer provenientes de las corrientes inmigratorias (BOIXADÓS, 2000). Las edificaciones completan las parcelas llegando a sus bordes y en general dejan un vacío central y/o patio al fondo dependiendo de las proporciones de los lotes. Disminución de parcelas y aumento de masa arquitectónica es la característica que marca la tendencia en el proceso de cambio del tejido edilicio que se dará a mediados del siglo siguiente.

En el periodo 2016 queda expuesta la diversidad de formas que son el resultado del paisaje actual. También queda expuesto en las siguientes imágenes la falta de correlación entre modelo de ordenanza actual y la realidad dado por muchos factores tales como cambios de ordenanzas, readecuaciones de las mismas, y excepciones, que será tema de profundización en una próxima etapa y motivo de una futura presentación de sus resultados. 

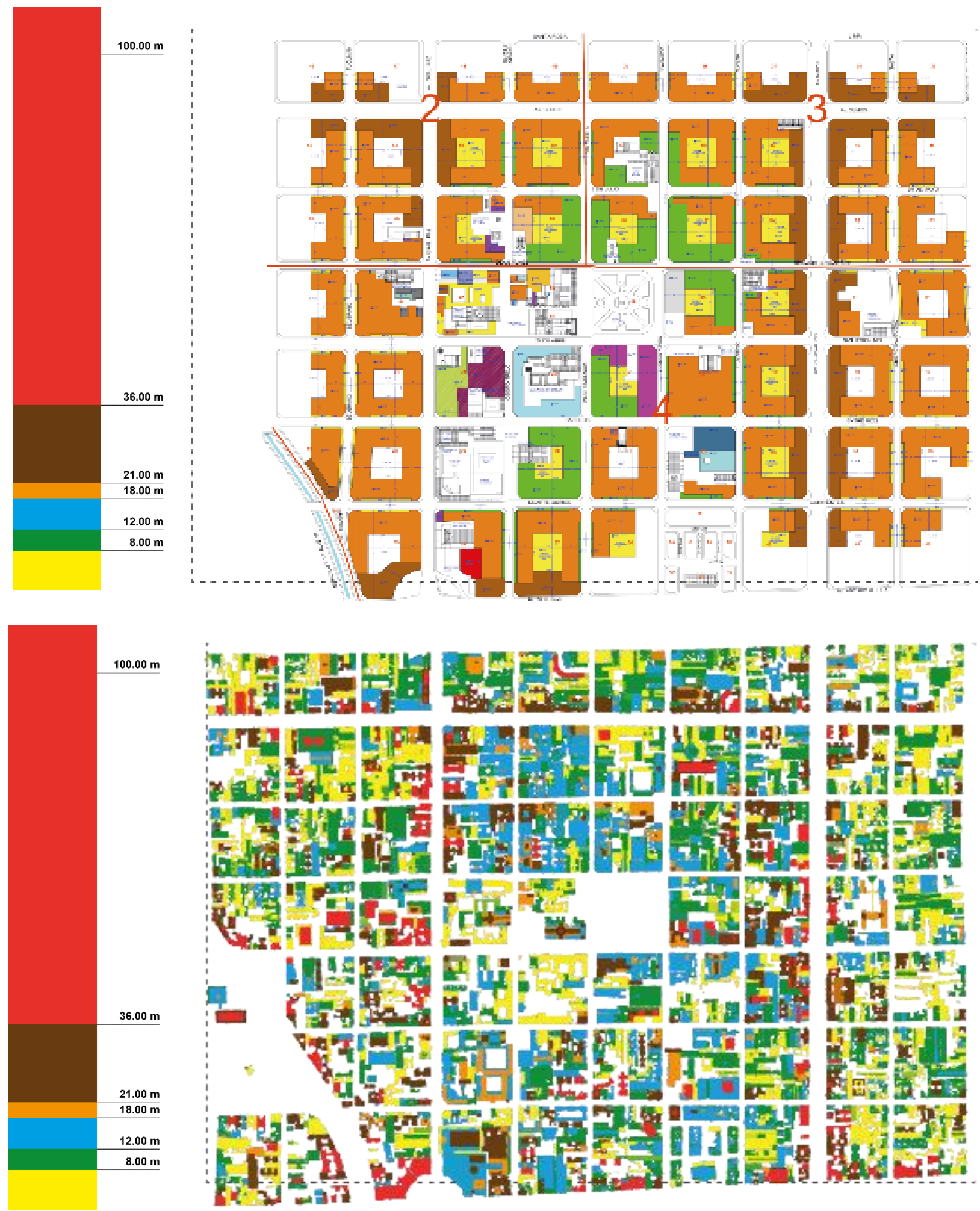

Año 2016. Arriba, planimetría con alturas definidas por la municipalidad de Córdoba para el área especial del centro historico. Nótese que las 70 manzanas no están contempladas como tal, quedando algunos de sus bordes. Abajo planta térmica de alturas. La escala va de 0 a 110 (que es el edificio más alto en la actualidad: Torre Ángela) y los saltos graduales responden a las alturas de la ordenanza actual para el sector de estudio. Nótese la diferencia de ubicación de los colores. Técnica, definición de malla térmica y aplicación sobre modelo tridimensional. Elaboración propia. 


\section{Bibliografía}

Ayuntamiento de Barcelona. (1983). Plan Especial del Ensanche de Barcelona. Barcelona: Ayuntamiento de Barcelona.

BOIXADÓS, M. (2000). La heterogeneidad de la trama urbana. En Las tramas de una ciudad, Córdoba entre 1870 y 1895. elite urbanizadora, infraestructura, poblamiento... Córdoba: Ferreyra Editor.

(2008). Córdoba fotografiada entre 1870 y 1930. Imágenes urbanas. Córdoba: Universidad Nacional de Córdoba.

COROMINAS I AYALA, M. (2002). Los orígenesdel Ensanche de Barcelona. Suelo, técnica e iniciativa. Barcelona: Ediciones UPC.

FOGLIA, M., GOYTIA, N., \& otros. (1987). La cuadrícula en el desarrollo de la ciudad hispanoamericana: caso Córdoba. 1573-1810. Córdoba: Universidad Nacional de Córdoba.

(1994). La cuadrícula en el desarrollo de la ciudad Hispanoamericana. El Caso de Córdoba. Tomo II. Córdoba: Universidad Nacional de Córdoba.

FORMAN, R., \& otros. (1995). Land Mosaics. The ecology of landscape and regions. Canbridge, Great Britain: University Press.

GALINDO GONZELEZ, J., \& SABATE BEL, J. (2009). el valor estructurante del patrimonio en la transformacion del territorio. Apuntes, 22(1), 20 a 33.

GOYTIA, N., \& FOGLIA, M. E. (1990). Procesos de modernización en Córdoba. Córdoba: Dirección de publicaciones de la FAUD, UNC.

HALL, P. (1996). Ciudades del mañana. Historia del urbanismo en el siglo XX. Barcelona: Ediciones del Serbal.

HARDOY, J. (1991). La forma de las ciudad coloniales en hispanoamérica. Cartografía urbano colonial de América Latina y el Caribe. Buenos Aires: Grupo editor latinoamericano.

HOFER, A. (2003). Karl Bruner y el urbanismo europeo en América Latina. Bogotá: El Ancora Editores/ Corporación La Candelaria.

IRÓS, G. (2007). Ciudad y Región. Córdona: Editorial de la Facultad de Arquitectura Urbanismo y Diseño de la UNC. Departamento de Publicaciones FAUDI.

LUQUE COLOMBRES, C. (1980). Orígenes históricos de la propiedad urbana de Córdoba (siglos XVI y XVII). Córdoba: Dirección general de publicaciones.

MUNICIPALIDAD DE CÓRDOBA. (1880). Archivo Municipal de Córdoba (Vol. Tomo I). Córdoba.

NASELLI, C. (1992). De ciudades, formas y paisajes. Asunción: Arquna ediciones.

(2013). Síntesis conceptual. En I. MOISSET, C. NASELLI, O. PARIS, V. COLAUTTI, I. PERIES, \& M. PEDRAZZANI, La ciudad en transformación, Forma Urbana 2. Córdoba: i+p.

NASELLI, C., MOISSET, I., PARIS, O., COLAUTTI, V., \& STEVENAZZI, C. (2006). Forma Urbana, lectura y acciones en la ciudad. Córdoba: i+p.

NICOLINI, A. (2001). La ciudad regular en la praxis hispanoamericana. Actas do Colóquio Internacional Universo Urbanístico Português 1415-1822. Lisboa: Comissão Nacional para as Comemoraçôes dos Descobrimentos Portugueses. .

PAGE, C. (1991). Propuestas e intervenciones urbanas en Córdoba 1880/1930. Cordoba: Departamento de publicaciones de la Facultad de Arquitectura- UNC.

(1996). Historia de la Arquitectura y el Urbanismo de Córdoba. Córdoba: Instituto de Investigación en Conservación del Patrimonio Arquitectónico y Urbano. FAUD- UNC.

PANERAI, P. R., CASTEX, J., \& DEPAULE, J. (1986). Formas Urbanas: de la manzana al bloque. (S. Castan, Trad.) Barcelona: GG.

PANERAI, P., \& Jean Charles DEPAULE, M. D. (1983). Elementos de análisis urbano . (I. d. Madrid, Ed., \& J. V. Lozano, Trad.) Madrid: Coleccion Nuevo Urbanismo.

PANERAI, P., \& MANGIN, D. (2002). Proyectar la ciudad. Madrid: Celeste Ediciones.

PARIS, O. (2012). La regularidad irregular. En M. P. Naselli, La ciudad en transformacion (pág. 42 a 60). Cordoba: $i+p$.

(2015). El proceso de subdivisión parcelaria y la configuración de la imagen heterogénea de la ciudad latinoamericana. Caso de estudio: ciudad de Córdoba, Argentina. actas del VII Seminario Internacional de Investigacion en Urbanismo (pág. 84 a 104). Montevideo: DUOT. Universidad Politecnica de Catalunya.

Programa de las Naciones Unidas para Asentamientos Humanos, O.-H. (2012). Estado de las ciudades de América Latina y El Caribe 2012. Rumbo a una nueva transición urbana. Río de Janeiro.

RETTAROLI, J. M., \& MARTINEZ, J. (1994). 1994. Córdoba: Departamente de publiaciones de la FAUD, UNC.

(1994). Evolución de la planta urbana de la ciudad de Córdoba. . Córdoba: Departamento de publicaciones de la FAUD, UNC. 
(1994). Evolución de la planta urbana de la ciudad de Córdoba. Tomo III. Periodo: primera expansión 1880-1930. Córdoba: Departamento de publicaciones de la FAUD, UNC.

RUEdA, S. (2007). Plan de Movilidad Sostenible y Espacio Público en Vitoria-Gasteiz. Agencia de Ecología Urbana de Barcelona. Ayuntamiento de Vitoria Gásteiz.

SABATÉ BELL, J. (julio de 1999). "Normativa Urbana" (entrevista). Propuesta Urbana.

SARMIENTO, D. F. (1845). Civilizacion y Barbarie, vida de Juan Facundo Quiroga. Santiago de Chile: imprenta del progreso.

STEVENAZZI, C. (2006). La unidad singular . En C. STEVENAZZI, C. NASELLI, O. PARIS, I. MOISSET, \& V. COLAUTTI, Forma Urbana. Lectura y acciones en la ciudad (págs. 86-103). Córdoba: editorial i+p.

WAISMAN, M. (1993). El interior de la historia - Historiografía Arquitectónica para uso de Latinoamericanos. Bogotá: Escala. 